ISSN: 0514-7336

DOI: https://doi.org/10.14201/zephyrus20177981101

\title{
SITUACIÓN DE TUMBAS CON AJUARES DE OBJETOS COTIDIANOS EN ALGUNAS NECRÓPOLIS CELTIBÉRICAS DE LOS SS. IV A II A. C.
}

\section{Grave goods tombs situation with everyday objects in some Celtiberian necropolis to the $I V^{t h}-I I^{\text {nd }}$ centuries $B C$}

\author{
Magdalena BARril ViCENTE \\ Museo de Cuenca. C/ Obispo Valero, 12. 16001 Cuenca. Correo-e: mbarril@jccm.es
}

Recepción: 12/02/2016; Revisión: 23/07/2016; Aceptación: 13/02/2017

Resumen: En algunas necrópolis del ámbito céltico hispano se hallan ajuares con elementos utilizados en la vida cotidiana. Piezas que nos remiten al hogar y a actividades productivas y/o económicas. Son objetos que en las tumbas se asocian a armas y/o a elementos de la indumentaria, formando conjuntos que acompañaban al difunto al Más Allá.

Entre los relacionados con el hogar incluimos trébedes, parrillas o asadores, cuya presencia en ajuares funerarios se interpreta en relación con la celebración de banquetes fúnebres. Son elementos de aparición esporádica en el ámbito celtibérico.

También se documentan útiles asociados a actividades agrícolas, ganaderas y artesanales, en ámbitos celtibéricos. Su presencia también es escasa, pero ofrece un variado repertorio, entre ellos hoces, podaderas, hachas, tijeras y leznas o punzones.

En este trabajo, se analiza su presencia y distribución espacial dentro de algunas necrópolis celtibéricas, para comprobar si es posible dilucidar si este tipo de objetos en los ajuares proporcionan información sobre la vida y espiritualidad de los difuntos. Para ello, y a modo de ensayo, se parte de los datos conocidos de una selección de necrópolis celtibéricas que publican los planos de distribución de las tumbas: Las Madrigueras, Riba de Saelices, La Yunta, El Altillo de Cerropozo de Atienza, La Mercadera y Numancia.

Palabras clave: ritual funerario prerromano; organización de tumbas; útiles para el fuego; útiles agrícolas; jefaturas; sacerdocio.

Aвstract: In some Hispanic Celtic cemeteries there are grave good with elements of daily life. Pieces related with home and productive and / or economic activities. They are objects in the tombs associated with weapons and / or items of clothing together into packages that accompanied the deceased to the afterlife.

Among those related to home we include trivets, grills or barbecues, whose presence in funerary objects is interpreted in relation with the celebration of funeral feasts. They are elements still sporadic appearance in the Celtiberian territory.

They are also documented tools to agricultural, livestock and craft economic activities, in Celtiberian areas. Their presence is also poor, but offers a varied repertoire, including sickles, pruning knives, axes, scissors and awls or punches.

In this paper, its presence and spatial distribution within some Celtiberian necropolis is analyzed to see if it is possible to determine whether these objects in the graves provide information on the life and spirituality of the deceased. To do this, and as a test, is part of the known data from a selection of Celtiberian cementerian 
published floorplans of graves: Las Madrigueras, Riba de Saelices, La Yunta, El Altillo de Cerropozo of Atienza, La Mercadera and Numancia.

Key words: Prerroman funerary ritual; burial organization; fire tools; farm tools; leadership; priesthood.

\section{Introducción ${ }^{1}$}

En necrópolis del ámbito céltico hispano se hallan algunos ajuares con elementos utilizados en actividades domésticas, productivas y/o económicas de la vida cotidiana. Suelen asociarse a ajuares con armas y/o elementos de indumentaria y todos ellos ofrecen datos sobre los difuntos, cuya espiritualidad, la de sus familiares y vecinos trascendía en sus creencias en el Más allá. Tradicionalmente, se ha venido considerando que los objetos depositados en las tumbas tenían un valor social y simbólico añadido al puramente funcional, pudiendo ser considerados como indicadores de la posición de su poseedor dentro de su comunidad y su familia (Lorrio, 1997: 130). Pero recientemente se está valorando la posibilidad de matizar estas apreciaciones, ya que en ocasiones esos objetos pueden ser los más queridos por la persona difunta en vida, los que sus familiares consideren que la distinguía o bien los que ellos mismos les dejaban como recuerdo para el Más allá, por lo que esos objetos serían "más próximos al individuo que a la comunidad, al sentimiento que al estatus" (Urbina y Urquijo, 2015: 150). Se trata de un tema de gran amplitud, por lo que este trabajo se elabora con el propósito de plantear la posibilidad de un ensayo que permita comparar la presencia o ausencia de estos elementos en ámbitos célticos de distintas zonas de la Meseta. Por ello, se ha considerado necesario restringir el ámbito de estudio a necrópolis celtibéricas publicadas con planos de situación de tumbas, con una cronología entre los ss. IV y II a. C., para en un futuro comparar los resultados con los necrópolis vetonas o vacceas donde parece que tenían una mayor presencia.

Son objetos que, solo en los últimos tiempos, han comenzado a ser motivo de estudios monográficos por sí mismos y a documentarse tanto en hábitats como en necrópolis. Incluimos:

1 Agradecemos a A. Martín Esquivel y S. Sánchez de la Parra el tratamiento digital de las figuras de este trabajo. a) Los relacionados con el fuego y el banquete: trébedes, pinzas o tenazas, morillos, parrillas, pinchos de hierro y asadores de bronce (Kurtz, 1982; Barril, 2012; Faro, 2015); b) los útiles agrícolas y artesanales: hoces para segar cereal o follaje; podaderas para podar y desbrozar; azadas y rejas de arado para preparar y sanear el terreno; tijeras de distintos tamaños y funciones como el esquileo, el textil o el aseo; hachas de leñador o carpintero; azuelas, y escoplos (Barril, 2002; Berzosa, 2005; Chapa y Mayoral, 2007); y se ha decidido también incluir c) los que hemos considerado útiles multifuncionales como los cuchillos, considerados a veces como armas y otras como útiles domésticos o de sacrificio, dependiendo de su menor o mayor tamaño (Jimeno et al., 2004: 278; Mateos y Sánchez, 2014); los punzones biapuntados o leznas, en ocasiones relacionados con el modo de sujeción de los regatones al astil (Aguilera, 1916: 36; Lorrio, 1997: 234), pero que perfectamente podían haber ido enmangados y haber servido para perforar cueros o correajes (Jimeno et al., 2004: 281) y los mangos. Se ha excluido contabilizar la existencia de fusayolas y otros útiles cerámicos, ya que su amplia presencia podía distorsionar la muestra y posiblemente su inclusión en las tumbas indica la realización de una ofrenda más que una función (Barril y Salve, 2002; Jimeno et al., 2004: 284). Algunos de estos útiles se ha propuesto que estén representados en determinadas monedas que llevan una cabeza varonil en el anverso y un jinete en el reverso, que podrían interpretarse con la divinidad y el héroe ecuestre de la ciudad (Almagro-Gorbea, 1995), así por ejemplo los arados tras la cabeza varonil de algunas cecas, como Arsaos (CNH: 252 n. ${ }^{\text {os }}$ 1-2 y 253 n. ${ }^{\circ}$ 9) y Uarakos (CNH: 297 n.o 1) o bien las dudosas hachas dobles que llevan jinetes de $\mathrm{Ar}$ saos (CNH: 252 n. ${ }^{\text {os }} 1-2$ y 253 n. ${ }^{\circ}$ 9; Guadán, 1979: 55) o los vástagos curvos que sujetan en la mano derecha algunos jinetes en los reversos de cecas como Oilaunikos (cNH: 278 n. ${ }^{\circ} 1$ ) o Turiasu (CNH: 
262 n. ${ }^{\circ}$ 1), considerados por algunos investigadores cateias-especie de bumerán galo-, hoces, hoces guerreras o falx, planteándose que hayan podido emplearse como armas de carácter ritual (Guadán, 1979: 73). Es un tema sobre el que hay una discusión científica de difícil resolución actualmente, pues los excavadores opinan que la interpretación más lógica para la inclusión de estos elementos, de clara funcionalidad en lugares de habitación, en los ajuares funerarios es que se trata de objetos de prestigio que reflejarían el control de la producción agrícola o de la posesión de la tierra cuyo carácter simbólico puede estar yuxtapuesto o ser complementario al del resto de los objetos depositados. De igual modo las tijeras de esquileo podrían representar el dominio de la riqueza ganadera y la economía lanar (Lorrio, 1997: 233-234; Jimeno et al., 2004: 281-285).

Dentro de las necrópolis seleccionadas se han elegido las tumbas con ajuares que contenían alguno de los objetos utilitarios que acabamos de mencionar para el fuego, el banquete y distintas actividades que pueden relacionarse con la vida cotidiana. Estos objetos, que los arqueólogos encuadran bajo la denominación de 'utensilios' (Lorrio, 1997: 297-327; Jimeno et al., 2004: 274-294), suelen aparecer asociados a otros elementos como armas $\mathrm{u}$ objetos de indumentaria que han venido siendo tradicionalmente objetivo de estudios en profundidad. Por ello, habitualmente se incluyen dentro de: 1) ajuares de armas (lanzas y otras), con variantes por la presencia de espadas y/o puñales y sus vainas y variantes por presencia de elementos relacionados con el caballo; 2) ajuares con solo elementos de indumentaria y/o adorno, y 3) asociaciones de los elementos seleccionados entre sí.

\section{Necrópolis celtibéricas seleccionadas}

Las fronteras de la Celtiberia, que ocupaba el centro de la Península Ibérica, gran parte de la Meseta entre las cuencas del Ebro y el Tajo, parece que fueron cambiando a lo largo de los siglos y también

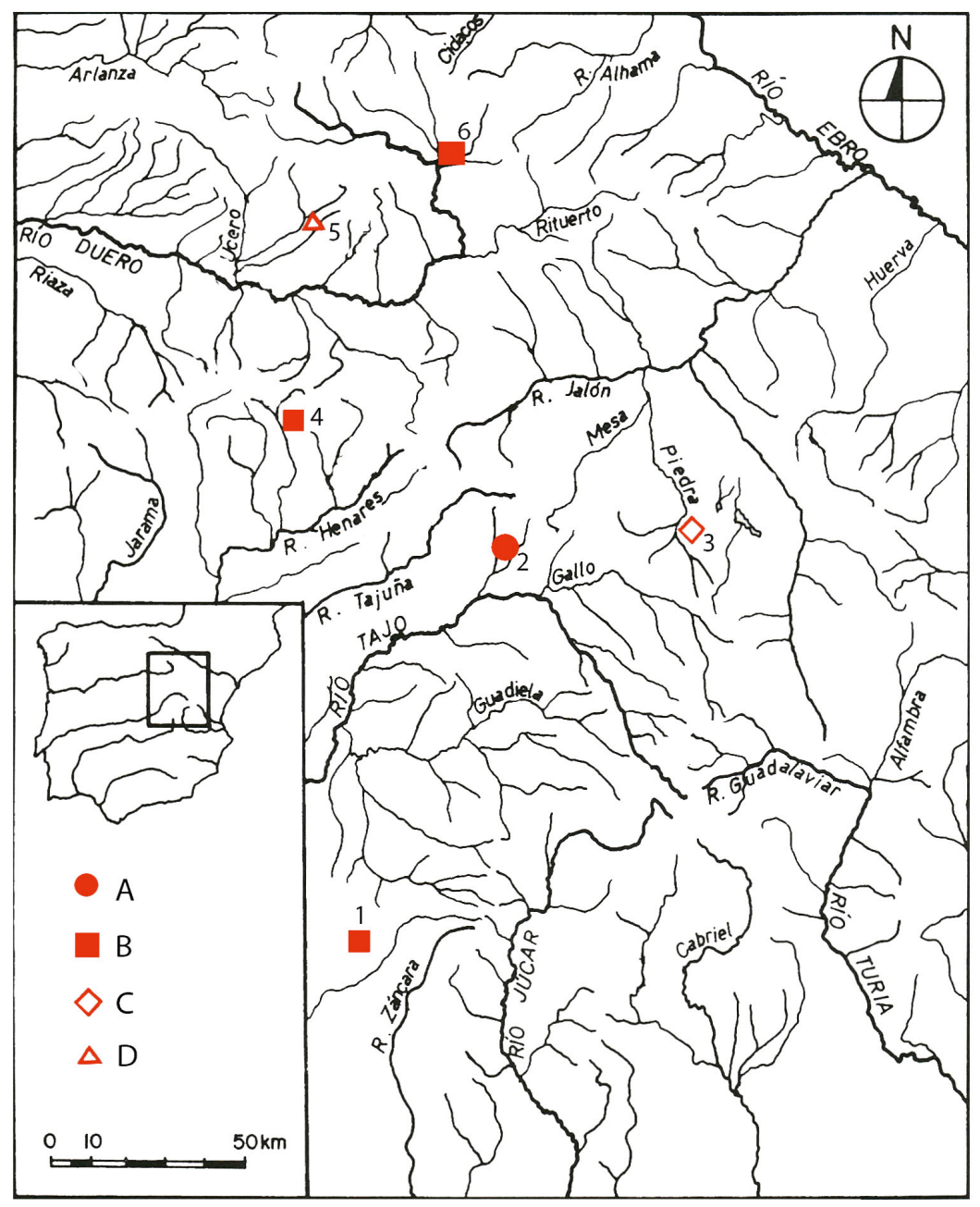

FIG. 1. Mapa de situación de las necrópolis seleccionadas (a partir de Lorrio, 1997: fig. 7 modificado): 1. Las Madrigueras, Carrascosa del Campo (Cuenca); 2. Riba de Saelices (Guadalajara); 3. La Yunta (Guadalajara); 4. Altillo de Cerropozo de Atienza (Guadalajara); 5. La Mercadera (Soria); 6. Numancia (Soria). Claves: A. Tumbas con estelas formando calles; $B$. Tumbas sin orden aparente con estelas; C. Tumbas sin orden aparente con túmulos; D. Mixta. 
la percepción que se tiene actualmente de ese territorio, ya que al tiempo que se conoce un mayor número de necrópolis se constata una mayor diferenciación entre ellas (Cerdeño y García-Huerta, 2001: 142; Burillo, 2005). Esas diferencias tal vez se potencien gracias a la búsqueda de raíces identitarias de las distintas comunidades (Ruiz Zapatero, 2005).

Debido a que hemos considerado relevante poder ubicar las tumbas con este tipo de útiles de trabajo y fuego en el conjunto del cementerio, no es posible incluir ciertas necrópolis muy conocidas en la bibliografía, en las que se registran ajuares con presencia de hoces, tijeras, rejas de arado o azadas, pero para las que no se han publicado planos de dispersión del conjunto de la necrópolis con tumbas identificables en el mismo, como pueden ser La Requijada de Gormaz y Uxama (Cabré, 1917; Fuentes, 2011) o La Revilla de Calatańazor (Ortego, 1983) en la provincia de Soria, y Turmiel en la de Guadalajara (Barril, 1993). Tampoco se han incluido algunas otras necrópolis de excavación más reciente, como la de Herrería, Guadalajara
(Cerdeño y Sargadoy, 2007), por ser cronológicamente más antiguas que las que aquí se analizan.

Las necrópolis celtibéricas seleccionadas (Fig. 1) se datan entre los ss. IV y II a. C. y se sitúan en torno a los valles del Duero y el Tajo o cerca de ellos, y no son una muestra exhaustiva de las publicadas. Se han elegido por sus características La Mercadera (Taracena, 1932; Lorrio, 1990) y Numancia (Jimeno et al., 2004) en la provincia de Soria; las del Altillo de Cerropozo de Atienza (Cabré, 1930), Riba de Saelices (Cuadrado, 1968) y La Yunta (García-Huerta y Antona, 1992) en la provincia de Guadalajara, y Las Madrigueras (Almagro-Gorbea, 1965 y 1969), en la de Cuenca, al n de la ciudad de Segobriga a la que Plinio $(3,25)$ definió como caput Celtiberiae, es decir, como lugar limítrofe de la Celtiberia, al menos en la fase final de la Cultura celtibérica (Lorrio, 2007: 273) y en la cabecera de un afluente del Guadiana. La muestra manifiesta diferencias entre unas necrópolis y otras, dado que en unas la presencia de armamento es muy notable, como es el caso de La Mercadera, Numancia y Altillo de Cerropozo, mientras que en las otras, Las

\begin{tabular}{|c|c|c|c|c|c|c|c|c|c|c|c|c|c|c|c|c|c|c|c|}
\hline N.o & & 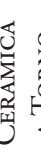 & & & & & & & & & & & 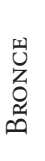 & & 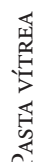 & & $\begin{array}{l}\text { O } \\
\text { 点 } \\
\text { 杢 }\end{array}$ & & 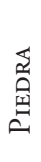 \\
\hline TUMBA ESTRATO & 胥 & $\begin{array}{l}0 \\
0 \\
5\end{array}$ & $\begin{array}{l}\text { ठ } \\
\text { Z } \\
\text { U. }\end{array}$ & 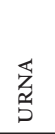 & 感 & $\begin{array}{l}\text { ठ } \\
\text { Z } \\
\text { 己े }\end{array}$ & 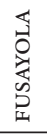 & 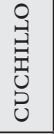 & 志 & 晃 & 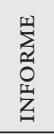 & 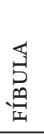 & 伨 & 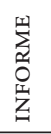 & 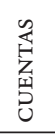 & 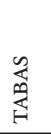 & $\begin{array}{l}8 \\
0 \\
z \\
\Sigma\end{array}$ & 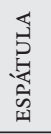 & 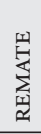 \\
\hline $\begin{array}{c}\text { VII } \\
\text { Est. II } \\
\end{array}$ & 1 & 2 & 1 & & & & 1 & & & & & & & 1 & & & & & \\
\hline $\begin{array}{c}\mathrm{X} \\
\text { Est. I }\end{array}$ & 2 & 3 & 2 & & & & 1 & & 1 & & & 3 & & & 7 & & & & \\
\hline $\begin{array}{c}\text { XI } \\
\text { Est. I }\end{array}$ & 1 & & 3 & & & & & 1 & & & & & & & & & & & \\
\hline $\begin{array}{c}\text { XII } \\
\text { Est. II }\end{array}$ & & 1 & & 1 & & & & & & 1 & & & & & & & & & \\
\hline $\begin{array}{l}\text { XXII } \\
\text { Est. I }\end{array}$ & 2 & & 1 & & & & 5 & & & & & 1 & 1 & 1 & 1 & 1 & & & \\
\hline $\begin{array}{c}\text { XLV } \\
\text { Est. II } \\
\end{array}$ & 1 & & 2 & & & & & & & & 5 & & & & & & 1 & 1 & \\
\hline $\begin{array}{l}\text { LXII } \\
\text { Est. II }\end{array}$ & 1 & 3 & 2 & & & & & & & & & & & & 1 & & & & 2 \\
\hline
\end{tabular}

Fig. 2. Selección de tumbas con ajuares con objetos-útiles de la necrópolis de Las Madrigueras. 


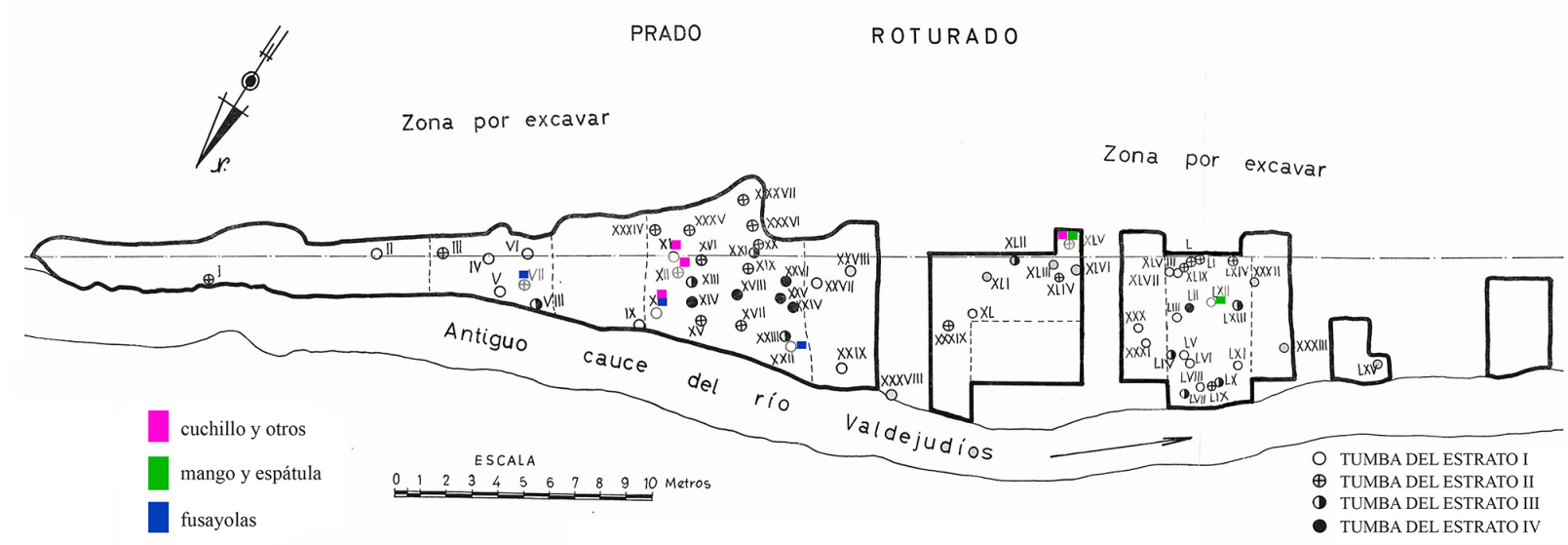

Fig. 3. Plano de la zona excavada de las necrópolis de Las Madrigueras con señalización de las sepulturas con objetos-útiles (a partir de Almagro Gorbea, 1969: fig. 3).

Madrigueras, La Yunta y Riba de Saelices, apenas hay presencia de armas, son escasos los ajuares con adornos o elementos de indumentaria y, en cambio, destacan sus recipientes cerámicos.

\subsection{Necrópolis de Las Madrigueras (Carrascosa del Campo, Cuenca)}

Se trata de una pequeña necrópolis (Figs. 2, 3 у 15в), situada cerca del límite meridional entre celtíberos y carpetanos, ya vertiendo aguas hacia el Záncara y que fue excavada parcialmente por M. Almagro Gorbea, quien documentaba cuatro estratos o fases, que, identificadas con el término municipal -Carrascosa- se han empleado como base para necrópolis de su entorno más meridional (Lorrio, 2007); terminología y asociación en revisión por Urbina y Urquijo (2007: 51 y 2015: 178). Se excavaron un total de 65 tumbas aparentemente sin orden, en algunos casos superpuestas y cuyo límite septentrional es el antiguo cauce del río Valdejudíos (Almagro-Gorbea, 1965 y 1969: 151, fig. 3), con áreas de ustrina entre zonas (Lorrio, 1997: fig. 3.2). Recientemente se han realizado nuevas excavaciones por motivos de urgencia, pero solo se han publicado resultados puntuales (Casas, Morín y Urbina, 2012).

Almagro Gorbea data las dos fases que identifica como más modernas a lo largo del s. IV y comienzos del III a. C., y en ellas se han documentado los escasos elementos relacionados con los útiles. Aunque Urbina y Urquijo (2015: 180) consideran que estas fases i y ir serían las de máximo apogeo de la necrópolis del Hierro in que finalizaría en la primera mitad del s. Iv a. C.

En este caso solo se han anotado dos tumbas con posibles útiles en hierro, un cuchillo en la XI (Almagro-Gorbea, 1969: fig. 20.1; Urbina y Urquijo, 2015: 179), lo que supone un $1,5 \%$ en el total de la necrópolis excavada; y un clavo en la XII, la primera del estrato i y la segunda del II, pero ambas situadas muy cercanas en la misma zona central, y trozos informes de hierro en otra sepultura, la XLV, del estrato II, donde coinciden con un mango que podría ser de un cuchillo y una espátula de hueso.

Además, en la sepultura LXII, del estrato I, según Almagro-Gorbea, situada al o de la necrópolis, se hallaron dos piedras talladas que sirvieron como remate de algún útil -punzón o huso según su excavador- en un ajuar que destaca porque incluía el pie recortado de un kylix ático entre otros elementos cerámicos y al que se considera elemento importado de prestigio presente en otras necrópolis cercanas como Haza del Arca, de Uclés (Lorrio, 2007: 264).

Es igualmente relevante destacar dos de las sepulturas con mayor número de objetos, la $\mathrm{x}$ y la XXII, ambas del estrato I y situadas en el centro de la necrópolis en dirección E-O, junto al borde del 
antiguo cauce del río. En la $\mathrm{x}$ se documentaron un total de 7 recipientes cerámicos, incluidas 2 urnas, y además 1 fusayola, 3 fíbulas, 7 cuentas y 1 anilla de hierro, que contabilizamos aunque desconocemos de qué objeto o útil formó parte. En la XXII el ajuar está constituido por objetos de adorno e indumentaria, 5 fusayolas, 1 taba, 2 urnas y 1 vasito precampaniense, pero ningún objeto que pueda considerarse un útil en los términos seleccionados para este trabajo. Es complicado encontrar un denominador común entre todos estos datos, ya que solo 5 sepulturas de las 65 excavadas contendrían algún elemento al que podamos considerar un útil o relacionado con ellos. Como hemos visto, de las 5 tumbas con algún elemento susceptible de ser considerado útil, 3 pertenecen al estrato $\mathrm{I}-$ sepulturas $\mathrm{x}$, XI y LXII- y 2 al II -sepulturas XII y XLV- por lo que las sepulturas con algún tipo de útil representan un $10,4 \%$ y un $9,5 \%$ dentro de sus respectivos estratos según Almagro-Gorbea. Ambos estratos suman un total de 50 tumbas, 29 en el i y 21 en el II, y el conjunto excavado un total de 65 sepulturas, por lo que esas tumbas representan un $7,7 \%$ en el total de la necrópolis publicada por su excavador.

\subsection{Necrópolis de Riba de Saelices (Guadalajara)}

E. Cuadrado excavó parcialmente esta necrópolis del antiguo término judicial de Cifuentes (Figs. 4 y 5), cuya existencia ya había conocido Cabré

\begin{tabular}{|c|c|c|c|c|c|c|c|c|c|c|c|c|c|c|}
\hline Tumba & \multicolumn{3}{|c|}{ CERÁmica } & \multicolumn{4}{|c|}{ Hierro } & \multicolumn{4}{|c|}{ BRONCE } & \multicolumn{3}{|c|}{ Hueso } \\
\hline N. ${ }^{\circ}$ & 䓀 & $\begin{array}{l}0 \\
\text { के } \\
\end{array}$ & 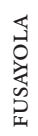 & 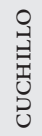 & 荘 & 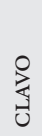 & 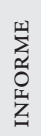 & 范 & 怘 & 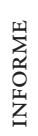 & 苞 & 粮 & $\begin{array}{l}0 \\
\text { O } \\
Z \\
\text { s }\end{array}$ & 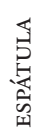 \\
\hline $\begin{array}{c}\text { Zona I } \\
\text { ustrinum }\end{array}$ & & & & 1 & & & & & & & & & & \\
\hline $\begin{array}{c}\text { Zona I } \\
\text { sepult. } 29\end{array}$ & 1 & & & 1 & & & & & & & & & & \\
\hline $\begin{array}{c}\text { Zona } 4 \\
\text { sepult. } 85\end{array}$ & 1 & & & & 1 & & & & & & & & & \\
\hline $\begin{array}{c}\text { Zona } 4 \\
\text { sepult. } 90\end{array}$ & 1 & & & 1 & & & & & & & & & 1 & \\
\hline
\end{tabular}

Fig. 4. Selección de tumbas con ajuares con objetos-útiles de la necrópolis de Riba de Saelices.
Aguiló. Cuadrado (1968) excavó cuatro zonas o áreas en 1964, que proporcionaron más de 102 tumbas alineadas en calles. Las zonas obtenidas tras la cuadriculación del espacio -unos $5.000 \mathrm{~m}^{2}$ - están trazadas a partir de la que denominó zona 1 cuyo eje vertical va de o a $\mathrm{E}$ y el horizontal de $\mathrm{S}$ a $\mathrm{N}$. Situándose la zona 2 hacia su $\mathrm{N}$ y la 3 y 4 hacia el s, según se deduce del plano elaborado por Cuadrado (1968: fig. 3). En las tumbas excavadas se hallaron muy pocos elementos de ajuar acompañando a las urnas funerarias cerámicas, y ningún arma.

Se hallaron tres cuchillos de hierro, uno en la zona 1 entre cenizas de un posible ustrinum (Cuadrado, 1968: fig. 17-5). El segundo en la tumba 91, también de la misma zona (Cuadrado, 1968: fig. 24-2) que conservaba restos de cachas de hueso, y un tercer cuchillo se halló en la tumba 29, de la zona 4 (Cuadrado, 1968: fig. 20-6), donde también había restos de su mango de hueso. Su presencia, por tanto, supone un $3 \%$ en el conjunto de la necrópolis, pero dado que uno de ellos carece de contexto, las otras dos tumbas con cuchillo suponen solo un 2\% en el conjunto de las 102 excavadas.

Cuadrado (1968: fig. 23-11) menciona en la sepultura 85 de la zona 4 una pieza a la que denomina palometa y que supone que atravesaría alguna madera. Aquí la definimos como grapa doblada en forma de asa y la hemos señalado en el plano de ubicación de las sepulturas. Cuadrado menciona también un trozo de varilla, que hemos comprobado se trata de una aguja de fíbula, no de un útil. Por tanto, en la zona 1 , que tiene treinta sepulturas, solo contabilizamos el cuchillo de la sepultura 91, la única con contexto, lo que supone un $3,4 \%$ de la zona $y$, en la zona 4 , que tiene veintinueve sepulturas, solo dos, las n. ${ }^{\text {os }} 29$ y 85 , tienen algún útil, representando un $6,9 \%$ de la zona. La situación de estas sepulturas dentro del conjunto de la necrópolis no parece indicar ningún lugar destacado. 


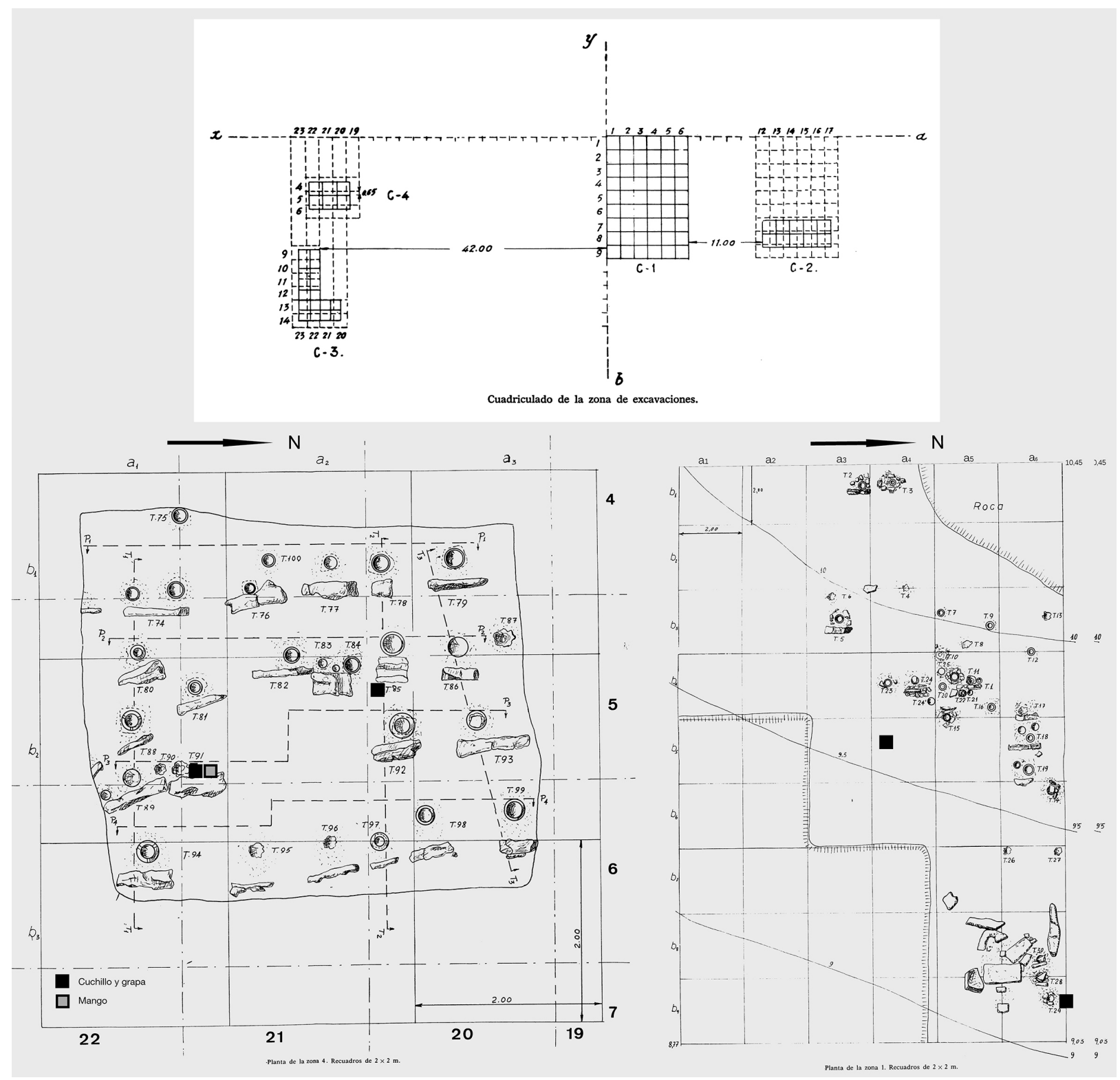

Fig. 5. Plano de la necrópolis de Riba de Saelices, zonas 4 y 1, con señalización de las sepulturas con objetos-útiles (a partir de Cuadrado, 1968: figs. 4, 8 y 5).

\subsection{Necrópolis de La Yunta (Guadalajara)}

Se excavó en esta necrópolis (Figs. 6, 7 y 15c) un total de 109 tumbas y hay constancia al menos de otras 18 que estaban alteradas. No obstante, los excavadores numeran 112, ya que agrupan varios números de sepulturas, 4 túmulos tienen numeración conjunta de túmulo y de sepultura; hay otros 6 túmulos y suponen que habría originariamente unas 250 tumbas (García-Huerta y Antona, 1992: 16-18).

Las tumbas se reparten en tres fases, la fase IA, la más antigua, con 27 tumbas, que datan de fines del s. IV a inicios del III a. C.; la fase IB, con 33 tumbas datadas en el s. III a. C. y de los túmulos corresponden cinco a cada una de estas subfases. En la fase II, 


\begin{tabular}{|c|c|c|c|c|c|c|c|c|c|c|c|c|c|c|c|c|c|c|c|c|}
\hline 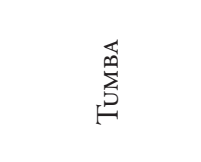 & 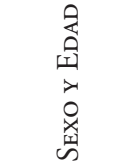 & & 通 & & & 岕 & & & & & & & & 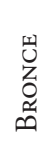 & & 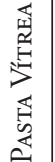 & & $\begin{array}{l}0 \\
\text { 畺 } \\
\text { 呈 }\end{array}$ & & 焉 \\
\hline N. ${ }^{\circ}$ & & 雍 & $\begin{array}{l}0 \\
\vdots \\
\text { th }\end{array}$ & $\begin{array}{l}8 \\
0 \\
\text { 勇 }\end{array}$ & 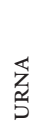 & $\begin{array}{l}0 \\
\text { Dे } \\
\end{array}$ & $\begin{array}{l}\text { O } \\
\text { Z } \\
\text { 苟 }\end{array}$ & 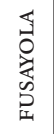 & 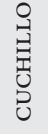 & 䒹 & 虎 & 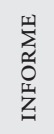 & 志 & 焉 & 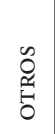 & 芦 & 童 & $\begin{array}{l}0 \\
0 \\
z \\
\Sigma\end{array}$ & 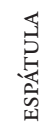 & 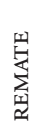 \\
\hline 1-Fase II & indet. & 1 & & 1 & & & & & & & & 1 & & & & & & & & \\
\hline 9-Fase II & & & & & & & & & & & & 1 & & & 2 & & & & & \\
\hline 11-Fase II & indet. & 1 & 1 & & & & & & & & & 3 & & & & & & & & \\
\hline 45-Fase III & $\begin{array}{l}\text { varón } \\
30 / 40 \\
\text { años }\end{array}$ & 1 & & 1 & & & & & 1 & & & & & & & & 3 & & & \\
\hline 68- Fase II & $\begin{array}{l}\text { varón } \\
50 / 60 \\
\text { años }\end{array}$ & 1 & 1 & 1 & & & & 1 & & & 1 & & 1 & 2 & & & & & & \\
\hline $\begin{array}{l}\text { 69-secundario } \\
\text { en Estructura G } \\
\text { Fase III }\end{array}$ & $\begin{array}{l}\text { varón } \\
40 / 50 \\
\text { ańos }\end{array}$ & 1 & 1 & & & & & & & & & & 1 & & & & & $\begin{array}{l}1 \\
\text { asta } \\
\text { dec. }\end{array}$ & & \\
\hline $\begin{array}{l}\text { 79-túmulo E } \\
\text { Fase Iв }\end{array}$ & $\begin{array}{l}\text { mujer } 40 \\
\text { años }\end{array}$ & 2 & 1 & 1 & & & & & & 1 & & & 1 & & & & & & & \\
\hline 87-Fase II & $\begin{array}{l}\text { varón } \\
40 / 50 \\
\text { años }\end{array}$ & 1 & & 1 & & & & & & 1 & 2 & & & & & & & & & \\
\hline $\begin{array}{l}\text { 112-túmulo D } \\
\text { Fase Iв }\end{array}$ & $\begin{array}{l}\text { mujer } \\
40 / 50 \\
\text { años }\end{array}$ & 1 & 1 & & & & & & & 1 & & 1 & & & & & & & & \\
\hline
\end{tabular}

Fig. 6. Selección de tumbas con ajuares con objetos-útiles de la necrópolis de La Yunta.

se documentan 52 tumbas solo en hoyo, datadas de fines del s. III al in a. C. (García-Huerta y Antona, 1992: 165-169).

Se trata de una necrópolis con escasa representación de armas, pues solo se registran en 12 tumbas, consistiendo en regatones y una vaina de puña, y apenas hay útiles. De hecho, solo se documenta un cuchillo hallado en la sepultura 45 de la fase Iв, lo que representa un $0,9 \%$ en el total de las 109 tumbas de la necrópolis y un 3\% dentro de las de su fase. Los restos del difunto, un varón de $30 \mathrm{a}$ 40 años, estaban en una urna con tapa y en la que como ajuar u ofrenda había tres tabas.
Dentro de la categoría de útiles incluimos un mango de asta decorado de la tumba 68, de la fase II, perteneciente a un varón de 50/60 años. Es una de las tumbas con mayor número de elementos de la necrópolis, pues además de la urna con una tapadera en forma de copa había un plato, una fusayola, una escarpia, una fíbula de hierro y dos placas de bronce. Esta tumba con útiles supone el 1,9\% de su fase. En el área excavada la tumba 45 -fase IB-, donde se halló el cuchillo, está situada hacia el centro de la necrópolis y la tumba 68 -fase II- en la periferia. 


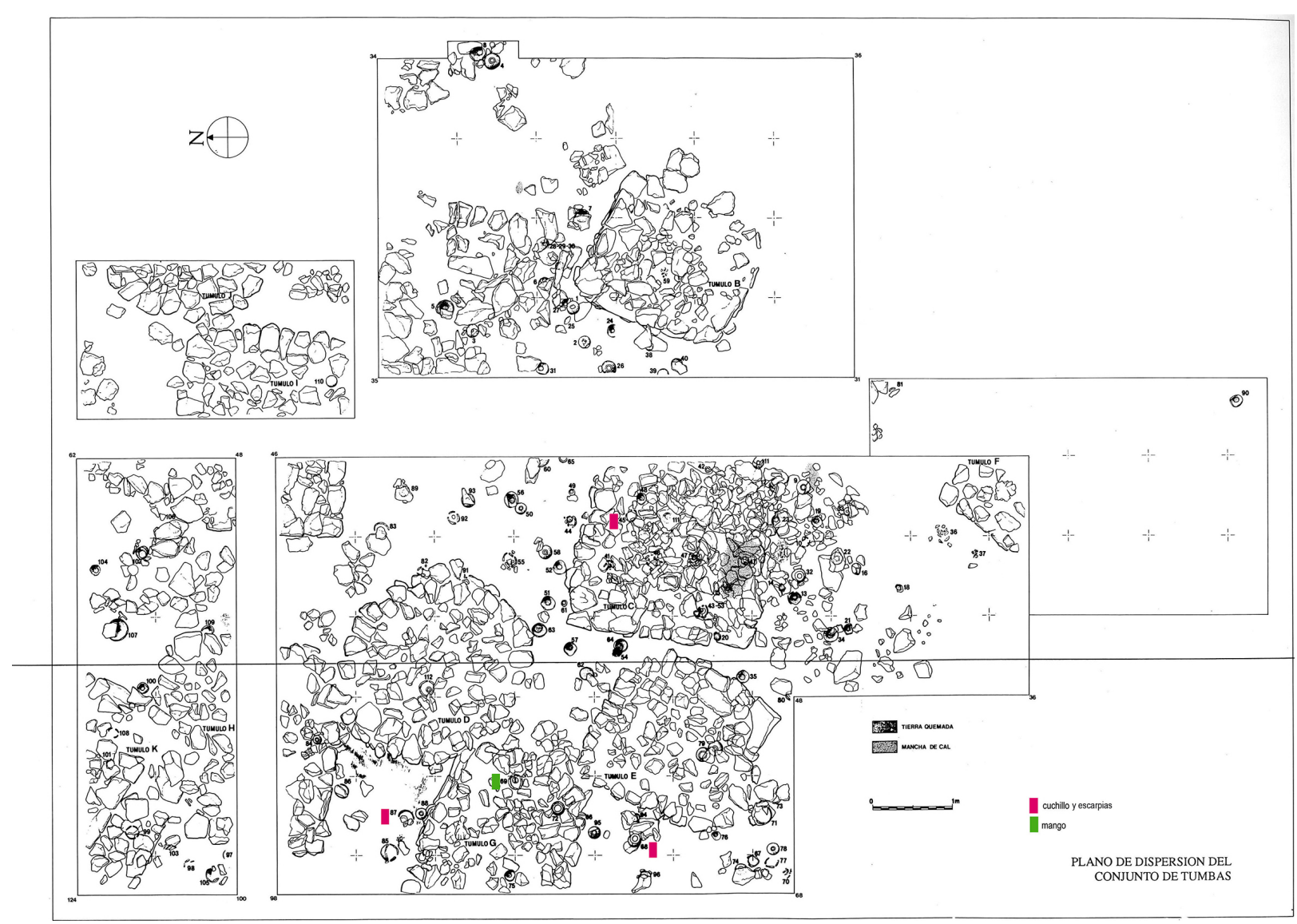

Fig. 7. Plano de la necrópolis de La Yunta con señalización de las sepulturas con objetos-útiles (a partir de García-Huerta y Antona, 1992: fig. 2).

\subsection{Necrópolis del Altillo de Cerropozo (Atienza, Guadalajara)}

Necrópolis excavada por Juan Cabré (1930) tras serle notificada la aparición de armas y otros objetos al hacer una carretera de Atienza a Hiendelaencina. Es junto con La Mercadera una de las primeras necrópolis celtibéricas publicadas describiendo claramente cada tumba, su situación y su ajuar. Se excavó un área de unos $2.036 \mathrm{~m}^{2}$, que era solo una parte de la necrópolis, la cual había sido muy dañada por las obras de la carretera.

Se trata de una necrópolis (Figs. 8, 9 y 15D) con tumbas aparentemente dispersas, quizás con alguna estructura tumular destruida y presencia de $u s-$ trina, donde el componente es claramente militar. Cabré excavó quince tumbas prerromanas $-n .^{\text {os }} 1-7$ y 9-16-, que incluían dos que consideró alteradas - n. ${ }^{\text {os }} 11$ y $14-$ y fosas interpretadas como ustrina -incluía la sepultura 17-. La revisión de Lorrio (1997: 331, fig. 46.2) propone que, dadas las características de los ajuares, pudiese haber un sector militar con mayoría de tumbas de armas con espada al SE, y otra con armas sin espada hacia el NO y, separada de éstas, una tumba con cuchillo por todo ajuar, la 7 , a la que considera más antigua. $Y$, situadas más al Este, las romanas. Además de estas sepulturas, Cabré enumera distintos objetos, armas y arreos de caballo, sin tumba definida, que procedentes de la caja abierta para la carretera le fueron entregadas por sus halladores. Estas piezas descontextualizadas procederían de la parte central del área excavada de la necrópolis, por lo que en el plano que se adjunta (Fig. 9) se han representado en la zanja de la carretera 


\begin{tabular}{|c|c|c|c|c|c|c|c|c|c|c|c|c|c|c|c|c|c|c|c|c|c|c|c|c|c|c|c|c|c|}
\hline N. ${ }^{\circ}$ Tumba & 菿 & 茫 & 茳 & 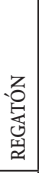 & 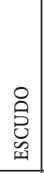 & 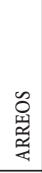 & 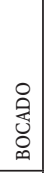 & 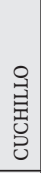 & 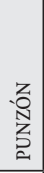 & 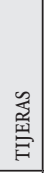 & 壳 & 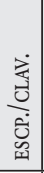 & 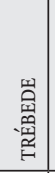 & 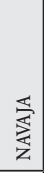 & 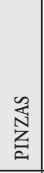 & 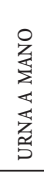 & 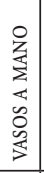 & 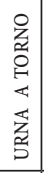 & 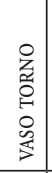 & 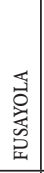 & 范 & 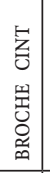 & 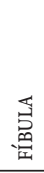 & 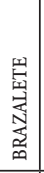 & 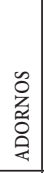 & 畜 & 芯 & 会 & 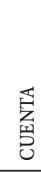 \\
\hline 1 & & & 2 & 1 & & & & 1 & & & 1 & & & & & & & 1 & & & & & & & & & & & \\
\hline $\begin{array}{c}1 \mathrm{~b} \\
\text { dama }\end{array}$ & & & & & & & & & & & & 1 & & & & 1 & 1 & & & & 1 & & & & 2 & & & & \\
\hline 2 & & & 1 & 1 & & & & & & & & & & & & & & & & & & & & & & & & & \\
\hline 3 & & & 2 & 2 & & & 1 & 2 & & & 1 & & & & & & & & & & & & 1 & & & & & 3 & \\
\hline 4 & & & 1 & & & & & 1 & & & & & & & & & & & & & & & & & & & & & \\
\hline $4 \mathrm{~b}$ & & & 2 & & & & 1 & & & & 1 & & & & & & & & 1 & & & & & & & & 1 & & \\
\hline $\begin{array}{c}\text { entre } \\
4 \mathrm{y} 5 \mathrm{a}\end{array}$ & & & & & & & & & & & & & & & & & 1 & & & & & & 1 & 1 & & & & & \\
\hline $\begin{array}{c}\text { entre } \\
4 \text { y } 5 \mathrm{~b}\end{array}$ & 1 & 1 & & & & & & 1 & & & & & & & & & 1 & & & & & & & & & & & & \\
\hline 5 & & & 2 & & & & 1 & 1 & & & 2 & & & & & & & 1 & & & & & & & & & & & \\
\hline 6 & & & 1 & 1 & & & & 1 & & & & & & & & & & & & & & & & & & & & & \\
\hline & & & & & & & & 2 & & & & & & & & & & & & & & & & & 1 & 1 & & 1 & \\
\hline 7 & & & & & & & & 1 & & & & & & & & & & 1 & & & & & 1 & & & & & & \\
\hline 8 romana & & & & & & & & & & & & & & & & & & & & & & & & & & & & & \\
\hline quemado & & & & & & & & & & & & 2 & & & & & & & & & & & 1 & & & & & 2 & \\
\hline 9 & 1 & 1 & 2 & & 1 & 2 & 2 & 1 & 1 & & & & & & & & & 1 & & & & & & & & & & & 1 \\
\hline 10 & 1 & 1 & 2 & & & & & 2 & & & & & & & & & & & & 1 & 3 & & & & & & & & \\
\hline 11 & & & & & 1 & & & & & & & & & & & & & 1 & & & & & & & & & & & \\
\hline 12 & 1 & 1 & 2 & 1 & & 10 & 2 & 1 & & & & & & & & & & & asa & 3 & 5 & & 1 & & & & & & \\
\hline 13 & 1 & 1 & 1 & 1 & 1 & 2 & & 2 & & & & & & & & & & & & & & & & & & & & & \\
\hline $13 \mathrm{~b}$ & & 1 & & 1 & & & & 2 & & & & & & & & & & & & & & & & & & & & & vas \\
\hline $13 \mathrm{c}$ & & 1 & & 1 & & & & & & & 1 & 9 & & & & & & & & & & & & & & & & & \\
\hline 14 & & 1 & & 1 & & & & 1 & & & 2 & & & & & & & & & & & & & & & & & 3 & vas \\
\hline 15 & 1 & 1 & 1 & 1 & 1 & 8 & 2 & 1 & 2 & 1 & & & & 1 & 1 & & & & & & 1 & & & & & & & 1 & \\
\hline 16 & 1 & 1 & 2 & & & & 3 & 3 & 1 & & & & & & 1 & & & 1 & & & & 1 & 1 & & & & & 2 & \\
\hline $\begin{array}{c}\text { entre } \\
15 \text { y } 16 \\
\end{array}$ & & & & & & 2 & 1 & & & & & 13 & & & 1 & & & & & & & & & & 1 & & & & \\
\hline 17 bolsón & & & & & & & & & & & & & & & & & & & & & & 1 & & 1 & 2 & 1 & & & \\
\hline $17 \mathrm{~b}$ & & & & & & & & & & & & 7 & & & & & & & & & & & 1 & & & & & & \\
\hline zanja inicio & 4 & & 16 & & 1 & & 7 & 5 & & & & 10 & 1 & & & & & & & & 1 & & 1 & & & & & 2 & \\
\hline \multicolumn{30}{|l|}{ XVIII } \\
\hline \multicolumn{30}{|l|}{ XIX } \\
\hline $\mathrm{XX}$ & & & & & & & & & & & & & & & & & & & & & & & & & & & & & \\
\hline
\end{tabular}

FIG. 8. Selección de tumbas con ajuares con objetos-útiles de la necrópolis del Altillo de Cerropozo de Atienza.

los materiales que se hallaron, que son similares a los de las sepulturas numeradas, pero no pueden contabilizarse en ninguna tumba concreta.

Entre ellos destacamos la presencia de una trébede, similar a las que se documentan, por ejemplo, en el territorio vetón, en La Osera (Chamartín, Ávila)
(Baquedano, 2016: 432-462) y otras en el territorio berón, como en El Castillo (Castejón, Navarra) (Faro, 2015: 87). Hubiera sido de gran interés conocer su contexto exacto, ya que se trata de uno de los objetos ligados al fuego que participa en rituales relacionados con los banquetes funerarios y se 


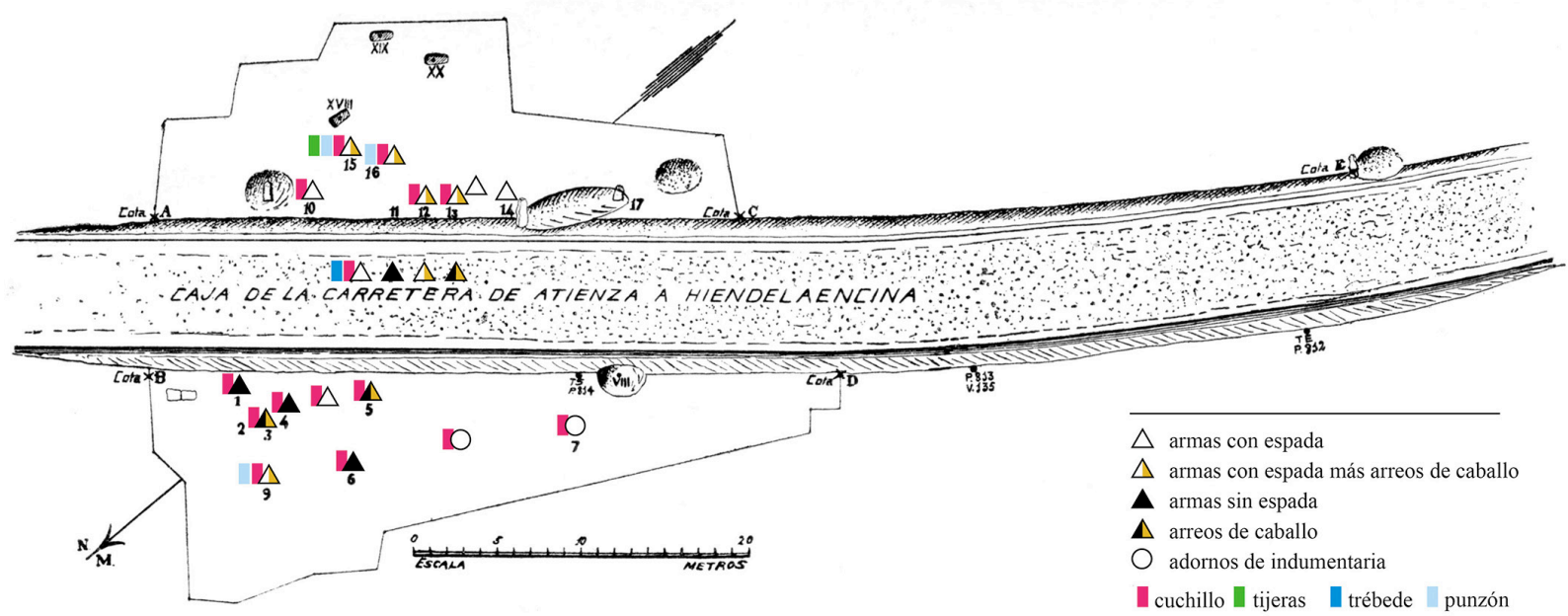

Fig. 9. Plano de la necrópolis del Altillo de Cerropozo de Atienza con señalización de las sepulturas con objetos-útiles (a partir de Cabré, 1930).

relacionan también con los emblemas del patriarca familiar o del sacerdocio que en su momento definió Kurtz (1982), y que solo en los últimos años han merecido estudios específicos tanto en el ámbito ibérico como en el céltico, proponiéndose que los espacios de habitación donde se han documentado tal vez fuesen habitaciones para celebrar cultos, debido a su escasa presencia (Pérez et al., 2011: 155).

Los otros elementos que nos interesan como útiles hallados en los ajuares del Altillo de Cerropozo son cuchillos, tijeras y punzones o leznas. Los cuchillos son aquí los útiles más representados; se hallaron en total 25 , en todas las sepulturas celtibéricas, excepto en las dos que se consideran alteradas -donde podrían haberse perdido-, más los hallados en los espacios entre sepulturas acompañados de otros materiales. Lo que en términos estadísticos, si solo contabilizamos las 15 sepulturas mencionadas, tendrían una presencia de un $86,67 \%$, aunque a la vista del número total de cuchillos hallados, su proporción en origen podría ser mayor. Se asocian a tumbas con armas con y sin espadas y, también, a tumbas que solo tienen objetos de indumentaria o adornos como ajuar. Destaca la sepultura n. ${ }^{\circ} 15$ por ser la única que tiene unas tijeras además del cuchillo y 2 punzones formando parte del equipo de guerrero. La documentación de este único ejemplar de tijeras supone un 6,67\% para el número de sepulturas indicado. Los otros 2 punzones se documentan uno en la sepultura 16, situada junto a la anterior y similar en contenido, con armas de asta y espadas, bocados de caballo y adornos u objetos de indumentaria, situadas ambas en la parte No, en el límite con las consideradas romanas; el tercer punzón pertenece a la sepultura 9, la única con armas, espadas y arreos de caballo que se sitúa en el área $\mathrm{NE}$, y lo hace en su borde. Estas tres tumbas con punzones son las de mayor riqueza de la necrópolis, suponen el 20\% del total señalado y, según hemos descrito y se refleja en el plano, están situadas en la periferia $\mathrm{E}$ y o del área excavada, aunque con modelos de espadas de antenas distintos, más antigua la de la sepultura 9 (Lorrio, 1997: 468); no vamos a entrar en las tipologías de las espadas, pero sí podemos plantearnos la posibilidad de que esta necrópolis comenzase a extenderse desde el Este hacia el o.

\subsection{Necrópolis de La Mercadera (Rioseco, Soria)}

Se trata de una necrópolis (Figs. 10, 11 y 15E) excavada por completo por B. Taracena en 1930, con una superficie irregular de unos $1.500 \mathrm{~m}^{2}$ y una densidad media de 0,07 tumbas $/ \mathrm{m}^{2}$. Fue revisada en 1990 por Lorrio a partir de la publicación de Taracena para establecer el grado de riqueza que reflejaban 


\begin{tabular}{|c|c|c|c|c|c|c|c|c|c|c|c|c|c|c|c|c|c|c|c|c|c|c|c|c|c|c|c|c|c|c|c|}
\hline $\begin{array}{l}\text { N.o } \\
\text { Tumba }\end{array}$ & $\begin{array}{l}\text { 死 } \\
\text { 荇 }\end{array}$ & 裳 & 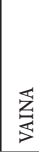 & 禁 & 壳 & 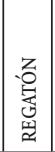 & 总 & 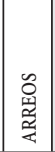 & 鼻 & $\begin{array}{l}z \\
\text { z } \\
\text { ż } \\
\text { L } \\
\end{array}$ & 옹 & $\begin{array}{l}\text { 喜 } \\
\text { 舆 }\end{array}$ & 莧 & $\frac{\text { 离 }}{\text { 总 }}$ & 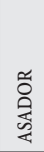 & 㞸 & 芯 & 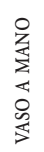 & 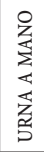 & 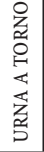 & 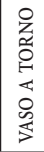 & 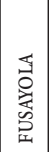 & 芯 & 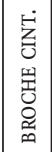 & $\begin{array}{l}\text { 志 } \\
\text { 量 }\end{array}$ & 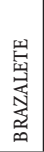 & 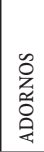 & 穿 & 芯 & 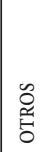 & 索 \\
\hline 1 & 1 & & 1 & & & & 1 & 1 & 1 & & 1 & & & & & & & & & & & & & & 1 & & 1 & & & & \\
\hline 3 & & & & & 2 & 3 & 1 & 1 & 3 & & 1 & & & & & & & & 1 & & & & & 2 & 1 & & & & & & \\
\hline 6 & & & 1 & & & & & & & & 1 & & & & & & & & & & & & & & & & & & & & \\
\hline 8 & & & 1 & & 1 & & & & 1 & & & 1 & & & & & & & & 1 & & & & & 2 & & & & & & \\
\hline 12 & & & & & & 1 & & & & 1 & & & & & & & & 1 & & & & & & & & & 1 & & & & \\
\hline 14 & 1 & & 1 & & 2 & & 1 & 1 & 1 & & 1 & 1 & & & 1 & & & & & & & & & & & & & & & & \\
\hline 15 & 1 & & 1 & & 1 & 2 & 1 & 1 & & 1 & & & & & & & & & & & & & & 2 & & & & & & & \\
\hline 16 & 1 & & 1 & & 2 & & 1 & 1 & 1 & & & & & & & & & & & & & & & & & & & & & & \\
\hline 19 & 1 & & 1 & & 2 & & 1 & & 1 & & & 1 & & & & & & & & & & & & & 2 & 1 & & & & & \\
\hline 26 & & & & & 2 & & 1 & & 1 & & & & & & & & & & & & & & & & & & & & & & \\
\hline 40 & & & & & 2 & & 1 & & 1 & & & & & & & & & 1 & & & & & & & & & 1 & & & & \\
\hline 41 & & & & & 2 & & & & 1 & & & & & & & & & & & & & & & & & & & & & & \\
\hline 47 & & & & & & & & & 1 & & & & & & & & & & & & & & & 1 & & & 1 & & & & \\
\hline 51 & 1 & & 1 & & 2 & & & & 1 & & & & & & & & & & & & & & & & & & & 2 & & 2 & \\
\hline 57 & & & & & 1 & & & & 1 & & & & & & & & & & & & & & & & 1 & & & & & & \\
\hline 58 & & & & & 2 & & 1 & & 1 & & & & & & & & & & & & & & & & 1 & & & & & & \\
\hline 60 & & & & & 2 & & 1 & & 1 & & & & & & & & & & & & & & & & 1 & & & & & & \\
\hline $66 a$ & & & & & 2 & & & & 1 & & & & & & & & & & & & & & & & 1 & & & & & & \\
\hline 67 & & & & & 2 & 1 & & & 1 & & & & & & & & & & & & & & & & & & & & & & \\
\hline 68 & 1 & & & & & & & 1 & 1 & 1 & 1 & 1 & & & & & & & & & & & & & & & & & & & \\
\hline 69 & & & & & 1 & & & & 1 & & & & & & & & & & & & & & & & 1 & & & 1 & & & \\
\hline 70 & & & & & & & & & & 1 & & & & & & & & & & & & & & & 1 & & 1 & & & & \\
\hline 72 & & & & & 2 & 1 & & 1 & 1 & & & & & & & & & & & & & & & 1 & & & & & & & \\
\hline 76 & & & & & & 1 & & & 1 & & & 1 & & & & & & & & & & & & & 2 & & & & & 3 & \\
\hline 78 & & 1 & 1 & 1 & & & & & & & & 1 & & & & & & & & & & & & & & & & 1 & & & \\
\hline 79 & & 1 & & & 1 & & & & & 1 & & & & & & & & & & & & & & & 1 & & & & & & \\
\hline 80 & & & & & 1 & & & & 1 & & & 1 & & & & & & & & & & & & & & & & & & 1 & \\
\hline 83 & & & & & 2 & & & & 1 & & & & & & & & & 1 & & & 1 & 1 & & & 1 & & & & & & \\
\hline 87 & & & 1 & & 1 & & & & 1 & & & & & & & & & & & & & & & & & & & & & 3 & \\
\hline 90 & & & & & 1 & & 1 & & 1 & & & & & & & & & & & & & & & & & & & & & . & \\
\hline 98 & & & & & 1 & & & & & 1 & & 1 & & & & & & & & & & & & & & & & & & 2 & \\
\hline
\end{tabular}

FIG. 10. Selección de tumbas con ajuares con objetos-útiles de la necrópolis de La Mercadera.

los ajuares de las tumbas, deduciendo que las tumbas de la necrópolis estaban agrupadas en cuatro zonas con mayor presencia de armas, en concreto de espadas. El mayor núcleo estaría situado en el centro de la necrópolis y al $\mathrm{N}$ y E estarían las zonas con ausencia de ajuar (Lorrio, 1997: 327). Se excavaron 99 tumbas, pero la 66 es doble, por lo que se considera que en total hay 100 tumbas y de ellas 45 contienen ajuar.

Los cuchillos se han hallado en 24 sepulturas, hoces o podaderas en 4 , tijeras en 8 sepulturas y punzones/leznas en 6 y asadores solo en 1. Hay una sepultura, la n. ${ }^{\circ}$ 68, en la que conviven los cuatro primeros útiles juntos y además hay una espada $\mathrm{y}$ quizás un resto de escudo, pero precisamente la ubicación de ésta falta en el plano publicado por Taracena. Llamamos la atención sobre otras dos sepulturas, las n. ${ }^{\circ} 3$ y 14 , que tenían una hoz-podadera. La n. 3 es la de mayor riqueza, como ya destacó Lorrio en 1990, y estaba acompañada de objetos de indumentaria, 3 cuchillos, arreos de caballo y escudo, 


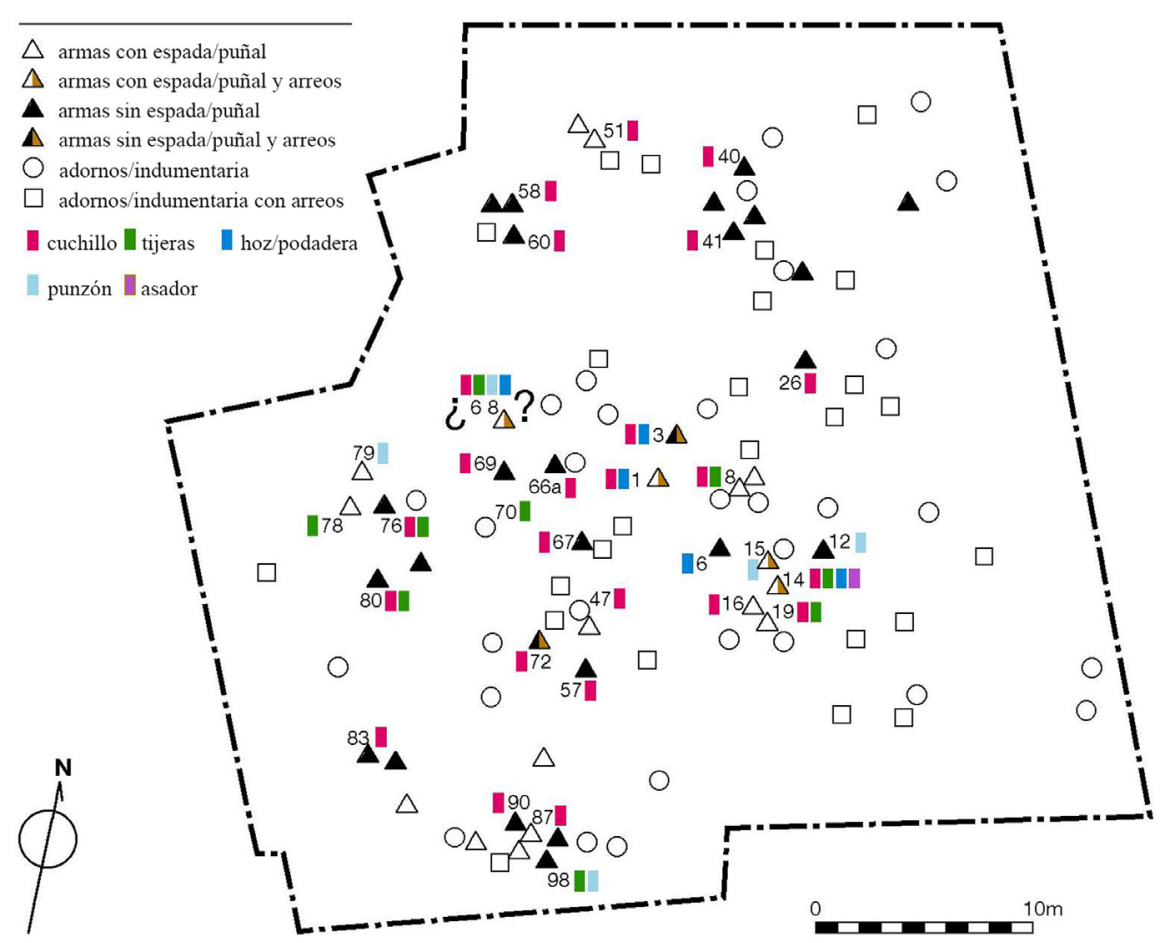

Fig. 11. Plano de la necrópolis de La Mercadera con señalización de las sepulturas con objetos-útiles (a partir de Lorrio, 1990: fig. 1).

pero es la única hoz que no está acompañada de una espada. La sepultura n. ${ }^{\circ} 14$ la destacamos, porque, además de ser otra de las de mayor riqueza, contiene el equipamiento de un jinete guerrero, 1 cuchillo, 1 tijeras, 1 hoz y además 1 o 2 asadores, siendo la única de la necrópolis que tiene en su ajuar algún elemento relacionado con el fuego y el banquete.

El porcentaje de presencia de útiles en los ajuares es por tanto elevado en relación con su ausencia, ya que suponen un $31 \%$ en el total de la necrópolis y un $61,9 \%$ en el conjunto de las que tienen ajuar. Además, las sepulturas que contienen hoces o podaderas parecen situarse en la zona central de la necrópolis, y las que tienen tijeras también en el eje central O-E, pero en los costados.

\subsection{Necrópolis de Numancia (Garray, Soria)}

Tras ańos de búsqueda por los arqueólogos esta necrópolis (Figs. 12, 13 y I 5F) fue localizada por furtivos en 1993. Tiene una superficie delimitada de unos $10.000 \mathrm{~m}^{2} \mathrm{y}$ fue excavada parcialmente por A. Jimeno y su equipo. Se han identificado 155 sepulturas, en su mayoría en hoyos, algunas rodeadas de piedras; alguna estela y manchas de tierras con carbones y huesos quemados. De forma global la necrópolis se data entre finales del s. III y el 133 a. C., ya que es la fecha de la destrucción de la ciudad por Escipión, con dos fases cronológicas. A la fase I, la más antigua, pertenecen 56 tumbas situadas en su zona central y a la II, algo más moderna, 99 tumbas repartidas por varias agrupaciones en su periferia (Jimeno et al., 2004: 301-302). La distribución de las partes excavadas de la necrópolis parece señalar un espacio con tumbas sin ajuar entre zonas de tumbas con armas. En ambas fases hay elementos que coinciden y las principales diferencias están en las armas, pues en la fase i se hallan espadas preferentemente de tipo lateniano y puñales de frontón $\mathrm{y}$ en la fase II puñales biglobulares.

En la publicación de las excavaciones se detallan en un capítulo los objetos contenidos en las tumbas con utensilios (Jimeno et al., 2004: 274-291), indicando que la mayoría documentan actividades domésticas: cuchillos, tijeras, leznas o punzones, agujas de coser, ganchos de carne y una posible trébede; actividades agrícolas, mediante hoces y podaderas, el trabajo de madera estaría representado por una cuchilla. Las tumbas en las que hay presentes algunos de estos objetos son 40, lo que supone un 25,8\% del total de sepulturas; de ellas 20 pertenecen a la fase I y otras 20 a la fase II, por lo que aunque el número sea el mismo la proporción dentro de cada conjunto es distinta, $35,7 \%$ y $20,2 \%$ respectivamente. Los 


\begin{tabular}{|c|c|c|c|c|c|c|c|c|c|c|c|c|c|c|c|c|c|c|c|c|c|c|c|c|c|c|c|}
\hline $\begin{array}{l}\mathrm{N} .{ }^{\circ} \\
\text { TUMBA }\end{array}$ & 营 & 壱 & 䓌 & $\underset{\mathbb{J}}{\mathrm{J}}$ & 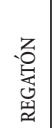 & 兽 & 总 & 员 & 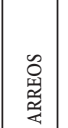 & 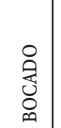 & 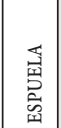 & 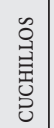 & $\begin{array}{l}\text { 羔 } \\
\text { 兽 }\end{array}$ & $\begin{array}{l}z \\
0 \\
z \\
z\end{array}$ & 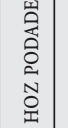 & 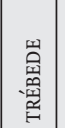 & 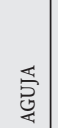 & 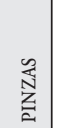 & 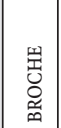 & $\begin{array}{l}\text { 志 } \\
\text { 畕 }\end{array}$ & \begin{tabular}{l}
0 \\
\multirow{3}{0}{} \\
0
\end{tabular} & 尊 & 总 & 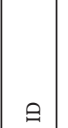 & \begin{tabular}{|l|} 
\\
$\tilde{c}$ \\
$\tilde{\tilde{g}}$ \\
\end{tabular} & 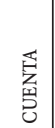 & 萬 \\
\hline 1 LT & 1 & 1 & 1 & 2 & & 1 & & & & & & & 1 & & & & & & & 1 & & & & $1 \mathrm{lt}$ & & & \\
\hline 2 & 1 & 1 & & 1 & 1 & & & & & & & & 1 & & & & & & 1 & 1 & & & & & & & \\
\hline 3 & & & & 1 & & & & & & & & 1 & 2 & 1 & & & & & & & & & & 1 & 1 & & 1 \\
\hline 4 LT & 1 & 1 & 1 & 2 & & & & & & & & 1 & & & & & & & & 2 & & & & & & & \\
\hline 5 & 1 & 1 & & 1 & 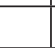 & & & & & & & 1 & & & & & & & & & & & & & & & \\
\hline 7 & & & & & 1 & & & & & & & & 1 & & & & & & & & & & & 1 & & & \\
\hline 18 & & & & 2 & & 1 & & & & & & & 1 & 1 & & & & & & 1 & & & & & & & \\
\hline 19 & & & & & 1 & & & & 8 & & & & & 1 & & & & & 1 & & & & & 1 & & & \\
\hline 20 & & 1 & & & & & & & & & & 1 & & & & & & & & & & & & & & & 1 \\
\hline 21 & & & & & & & & & 3 & & & & 1 & & & & & & 1 & 2 & & & & & 4 & & \\
\hline 22 & 1 & 1 & & & & & & 1 & \begin{tabular}{|l|}
10 \\
\end{tabular} & 1 & 1 & 1 & 1 & & & & 2 & 2 & & 3 & & & & & & & \\
\hline 25 & 1 & 1 & & 1 & & 1 & & & 1 & 1 & & 1 & 1 & & & & & & & & & & & & & & \\
\hline 26 & 1 & 1 & & 1 & & & & & 1 & 1 & & 1 & & 1 & & & & & & & & & & & & & \\
\hline 29 & & & & & & 1 & & & 1 & & 1 & 1 & 1 & & & & & 1 & & 1 & & & & & & & \\
\hline 33 & & & & & & & & & & & & & & 1 & & & & & & 1 & & & & 1 & 1 & & \\
\hline 40 & & & & & & & 3 & 1 & & & & & 2 & & & & & & 1 & 13 & & 1 & & & 3 & & \\
\hline 47 & 1 & 1 & & 2 & 2 & 1 & & & & & & & 2 & 1 & & & & 1 & 1 & 3 & & & & & & & \\
\hline 48 & & & & 1 & 1 & & & & & & & 1 & & & & & & 1 & & 1 & & & & & & & \\
\hline 50 & & & & & & & & & & & & 1 & & & & & & & 1 & 1 & 1 & & & 1 & 4 & & \\
\hline 51 & & 1 & & & & & & & & & 1 & & & 1 & & & 1 & 1 & 1 & 1 & & & & 2 & & & \\
\hline 52 & & 1 & & 1 & 2 & 1 & & & & & & & 1 & 1 & & & & & & 1 & & & & 2 & & & \\
\hline 54 & 1 & 1 & & 2 & & 1 & & & & & & 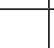 & 1 & & & & & & 2 & 1 & & & & & 1 & & \\
\hline 55 & & 1 & & 1 & 1 & & & & & & & 1 & 2 & & & & & & & 2 & & & & & & & \\
\hline 60 & 2 & 1 & & 2 & 1 & 1 & & & & & & & 1 & 1 & & & & & 1 & 1 & 2 & & & & 1 & & \\
\hline $61 \mathrm{LT}$ & 1 & 1 & 1 & 2 & 1 & & 1 & & & & & & 1 & 2 & 1 & & & & & 2 & 3 & & & & & & \\
\hline 62 & 1 & & & 1 & & & & 1 & & & & 1 & & & & & & & & 1 & & & & & & & \\
\hline 63 & & & & & & & 1 & & 7 & & & 1 & & 1 & & & & & & & & & & 1 & & & \\
\hline 65 & & & & & & & 1 & & & & & & 1 & & & & & & & 2 & & & 1 & & & & \\
\hline 80 & 1 & 1 & & & 2 & 1 & 1 & & & & & & 1 & & & 1 & & & & & 1 & 1 & & 1 & & & \\
\hline 90 & & & & & 1 & & & & & & & & 1 & & & & & & & 2 & 1 & 1 & & & 2 & & \\
\hline 91 & 1 & 1 & & & & & & & 5 & & & 2 & & & & & & & & 1 & & 1 & & 1 & & 1 & \\
\hline 103 & 1 & & & 1 & & & & & 4 & & & 1 & & & 1 & & & & & & & & & & & & \\
\hline 109 & & & & 1 & & 1 & & & & & & & 1 & & & & & & & 1 & & & & & & & \\
\hline 129 & & & & 2 & & 1 & & & & & & & 1 & 1 & & & & & & & & & & & & & \\
\hline 132 & 1 & & & & & & & & 1 & & & 1 & & & 1 & & & & & & & & & & & & \\
\hline 139 & 1 & 1 & & 3 & 1 & . & & & 1 & 1 & & 1 & & 1 & 1 & & & & 1 & & & & & & & & \\
\hline 144 & & & & & & 1 & & & & & 1 & 1 & 2 & & 1 & & & 2 & & 10 & & & & & 12 & & \\
\hline 148 & & & & & & & & & & & & 1 & & & & & & & & & & & & & & & \\
\hline 151 & 1 & 1 & & & & & & & & & & 1 & 2 & & & & & 1 & & 2 & & & & 2 & 1 & & \\
\hline 152 & & & & & & & & & & & & 1 & & & & & 1 & & & & & & & 2 & & & 1 \\
\hline
\end{tabular}

FIG. 12. Selección de tumbas con ajuares con objetos-útiles de la necrópolis de Numancia; LT=La Téne.

excavadores hacen además mención a otros útiles en referencia a las actividades textiles que representarían las fusayolas y a la presencia de clavos para unir pequeños elementos de madera, canicas y otros objetos no determinados como abrazaderas, que no hemos incluido en este trabajo. 


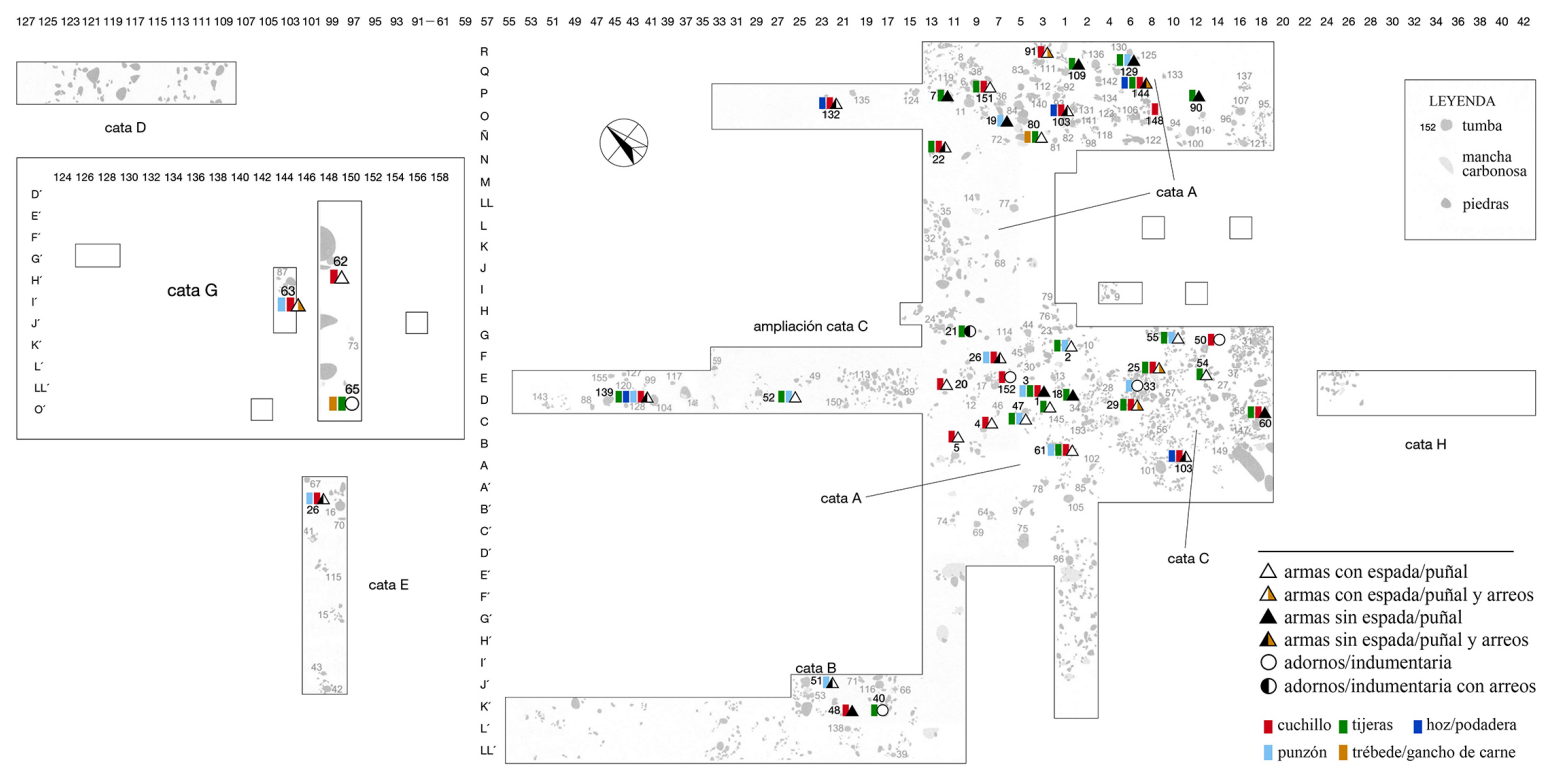

FIG. 13. Plano de la necrópolis de Numancia y detalle (a partir de Jimeno et al., 2004: 42-43, fig. 15) con señalización de las sepulturas con objetos-útiles.

Las asociaciones de los útiles a ajuares con armas y/o con objetos de adorno e indumentaria es muy alta, y en algunos casos, como el de la tumba 40, es posible que si hubiésemos recogido esa anotación en una excavación antigua hubiésemos desconfiado de su veracidad, ya que el ajuar lo componen dos tijeras, trece fíbulas, un broche, una placa y apliques, junto a restos de escudo y un clavo. Esta tumba está situada en la periferia de la necrópolis, pero en su parte central, en la cata в.

Los cuchillos están presentes en 23 sepulturas, lo que supone el $57,5 \%$ de las tumbas con ajuar y el $14,8 \%$ del total, aunque hay una, la 91 , que tiene 2 cuchillos.

Las tijeras tienen una presencia superior a la de los cuchillos ya que se documentan en 27 ajuares, un $17,4 \%$ del total y un $67,5 \%$ de las sepulturas con ajuar, aunque 4 de ellas tienen dos juegos de distintos tamańos.

Los punzones aparecen en 12 sepulturas, un $7,7 \%$ del total y un $30 \%$ de las sepulturas con ajuar y destaca que solo en 6 casos están asociados a regatones y en 2 a tumbas sin ningún tipo de armas.

En 3 sepulturas se han hallado hoces y en otra una podadera. Las tres sepulturas con hoces están asociadas a armas con espadas y cuchillo, pero ubicadas en zonas distintas y presentan algunas características reseńables. La 103, ubicada en la zona nuclear, se asocia a arreos de caballo; la 132, situada en la periferia NE - parte superior del plano- tiene similar asociación. La 139 está situada al o del área central de la necrópolis - una zona con sepulturas sin útiles- y se acompaña además de punzón, tijeras y un broche. Por su parte, la sepultura 144 , situada en la misma zona que la 132, contiene una podadera, carece de armas de asta y espada, pero sí tiene restos de escudo y arreos de caballo, incluyendo una espuela y, además, unas tijeras, unas pinzas, diez fíbulas y apliques; por lo que ese conjunto parece indicar que el difunto era un personaje que parece que cuidaba su aspecto.

En la necrópolis se han documentado varias zonas con restos de fauna quemada y otros elementos que hacen pensar en rituales de banquetes y fuego, pero solo se han hallado dos objetos que presumiblemente podrían haber participado en ellos. Uno es la trébede de la sepultura 80, situada al NE, en el área de la periferia superior del plano, considerada una de las tumbas más completas en lo que a armamento e indumentaria se refiere, también con tijeras, pero sin arreos de caballo. 
La otra sepultura con un posible elemento relacionado con estos rituales es la tumba 65, con un gancho de llar asociado a tijeras y a objetos de indumentaria, situada en el punto $s$ más periférico -extremo derecho inferior del plano-.

\section{Situación de las tumbas estudiadas en sus necrópolis}

En el conjunto de las necrópolis celtibéricas seleccionadas cuya situación geográfica se refleja en la Fig. 1, se aprecian dos grupos de necrópolis (Fig. 14), tal vez sectores de necrópolis mayores sin explorar completamente. Uno es el de las necrópolis más orientales y meridionales, que son Las Madrigueras, Riba de Saelices y La Yunta, que tiene ajuares con pocos objetos utilitarios, en proporción inferior a un $10 \%$ y donde los únicos útiles presentes son cuchillo, mangos de hueso o piedra, y algún otro elemento férreo o sobre hueso. En estas necrópolis apenas se han documentado algunas armas en La Yunta y se trata de armas de astil, muy distintas al menos en la parte excavada con otra necrópolis de la provincia de Guadalajara (Lorrio, 1997: 114), como es la famosa y clásica de Aguilar de Anguita, donde en algunas tumbas sí se hallaron importantes

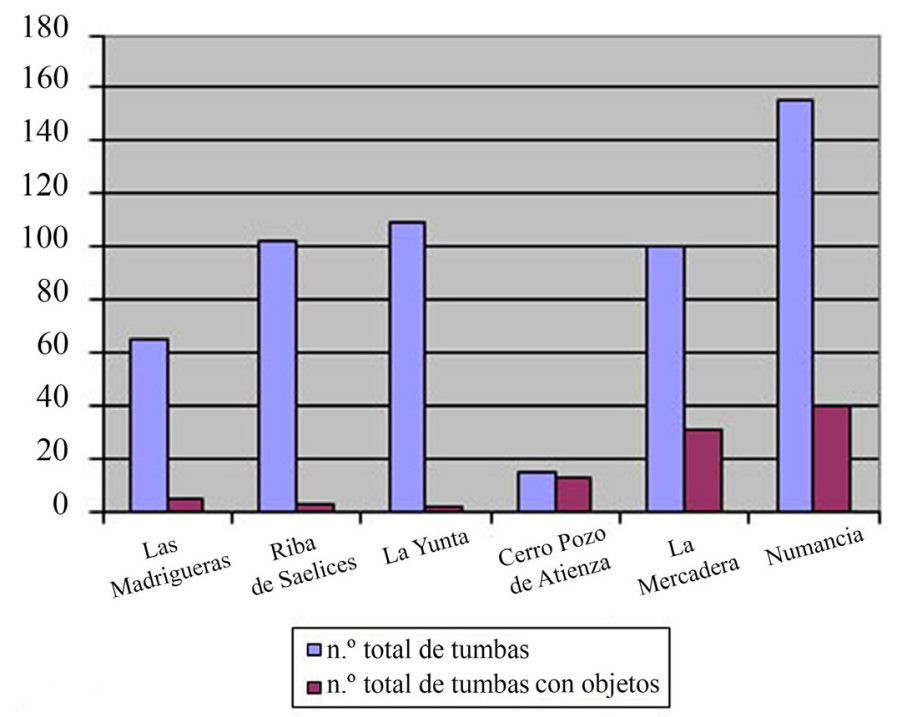

FIG. 14. Comparativa del total de ajuares y de los ajuares que contienen objetos-útiles en las necrópolis estudiadas. ajuares con armas, y más parecida a la de Luzaga y a las tumbas excavadas por Argente (1977), también en Aguilar de Anguita, de cronología equiparable.

Las otras 3 necrópolis seleccionadas para este trabajo se sitúan más a o y al N, son las del Altillo de Cerropozo de Atienza, La Mercadera y Numancia, donde se aprecian sectores con mayor presencia militar, muchos ajuares asociados también a objetos de indumentaria y a útiles agropecuarios o artesanales susceptibles de ser usados también como armas o como ayuda a tareas y actividades cotidianas, relacionadas con la recolección, el esquileo o la guarnicionería, en proporciones muy superiores al 10\% del total de la necrópolis, debiendo contemplarse su relación con la presencia de armas o adornos en los mismos ajuares. La asociación exclusiva de alguno de estos útiles a tumbas sin armas y con adornos suele reducirse a los punzones o leznas.

La situación de las tumbas que contienen los objetos no parece tener una especial localización centro-periferia común en el conjunto de las necrópolis, pero sí se integran plenamente en las zonas de cada una de las necrópolis con ajuares de composición similar, en particular esto se aprecia en las que contienen tijeras, hoces, podaderas o elementos para el fuego y el banquete, por lo que su presencia en el ajuar sí parece ser indicativa de una intencionalidad propiciada por el propio difunto o por sus allegados. La motivación que llevó a depositar esos objetos junto a los restos del difunto y el resto del ajuar pudo ser jerárquica, simbólica o simplemente afectiva, en cualquier caso parecen coincidir con las tumbas de mayor riqueza.

\section{Valoración de los útiles documentados}

Los distintos objetos (Fig. 15) cuya ubicación en las sepulturas y su asociación a otros elementos se pueden observar en los distintos planos que acompañan este trabajo son, como ya se ha indicado al comienzo, elementos que hallados en lugares de habitación tienen una finalidad doméstica, artesanal o agropecuaria, 

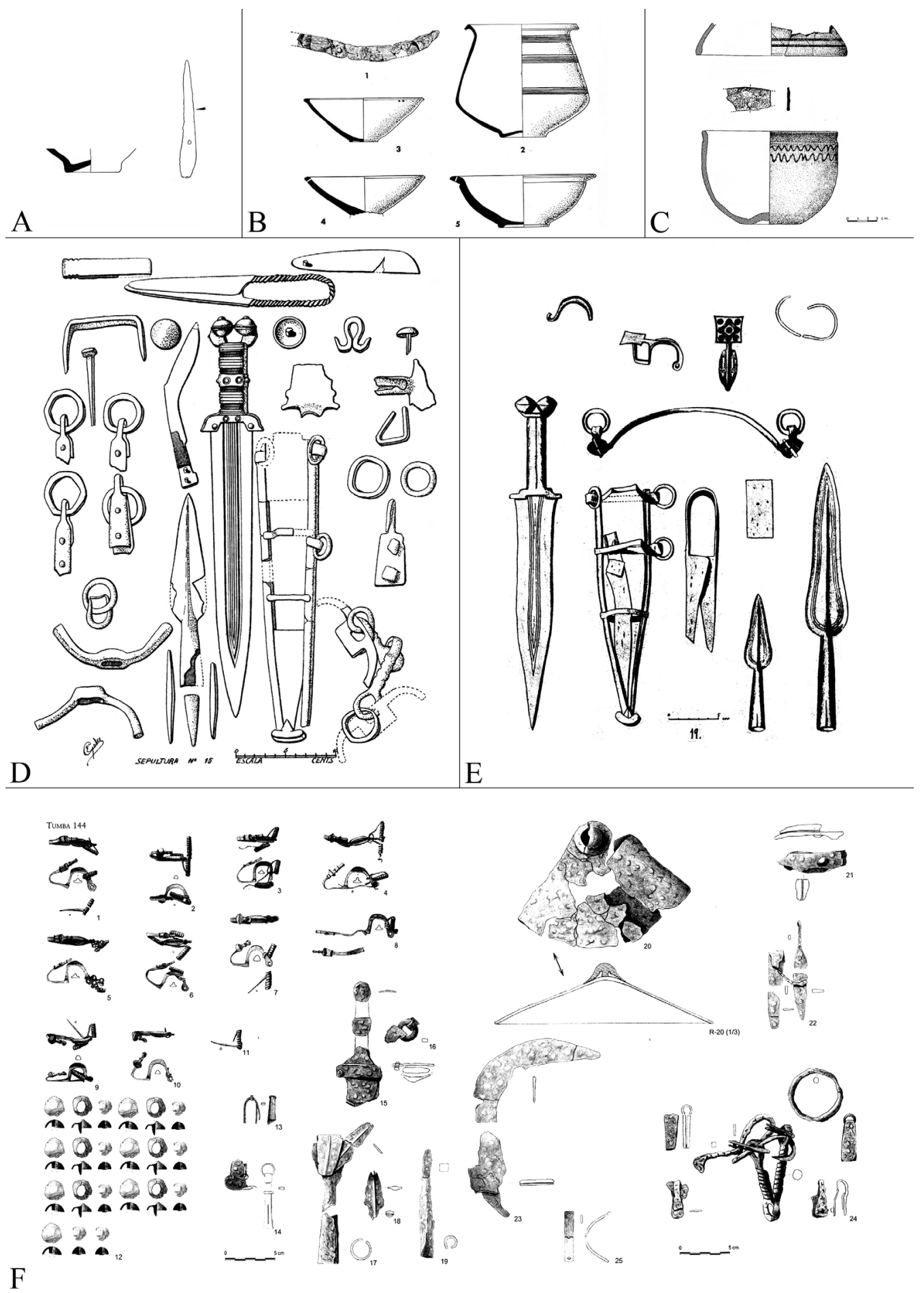

Fig. 15. Ajuares: A) Tumba 29 de Riba de Saelices, Fase I (Cuadrado, 1968: fig. 20.6); B) Tumba XI de Las Madrigueras, Fase II (Almagro-Gorbea, 1969: fig. 20); C) Tumba 45 de la Yunta, Fase IB (García-Huerta y Antona, 1992: fig. 41); D) Tumba 15 del Altillo de Cerro Pozo, Atienza (Cabré, 1930: lám. XVI); E) Tumba 19 de La Mercadera (Taracena, 1932: lám. III); F) Tumba 144 de Numancia (Jimeno et al., 2004: fig. 108a y b). 
pero depositados en sepulturas adquieren un significado simbólico relacionado con la posición familiar, social o el deseo del difunto. Algunos de ellos se consideran además útiles multifuncionales dado que pueden tener distintos usos según el contexto o bien han recibido distintas interpretaciones a lo largo del tiempo, como ya se ha indicado en algunos casos.

Los punzones biapuntados o leznas, por ejemplo, fueron considerados como elementos de sujeción del astil de una lanza a su regatón y parece que, en efecto, pudieron usarse de esta forma (Aguilera, 1916: 36; Lorrio, 1997: 234), sin embargo, al aparecer en muchas sepulturas como único elemento junto a algunos adornos confirmaría que fueron utilizados como útiles, relacionados con trabajos textiles o de guarnicionería (Jimeno et al., 2004: 281; Baquedano, 2016: 429).

Los cuchillos, como hemos visto, aparecen mayoritariamente en tumbas con armas, frecuentemente introducidos en el cajetín de la vaina de la espada y acompañando a lanzas y regatones y, en ocasiones, a tijeras y también en algunas tumbas que se suponen femeninas, sin armas, pero con algún punzón. Es una de las razones por las que frente a la idea tradicional que consideraban a este útil cortante un arma, se ha extendido el considerarlo un útil multifuncional ligado entre otras finalidades al sacrificio de animales (Faro, 2015: 44), aunque para ello se preferirían los cuchillos de mayor tamaño (Quesada, 1997: 166-168). Así en territorio vacceo se vincula la presencia de cuchillos al banquete (Sanz, 2010: 341), aunque esté mayoritariamente ligado a ajuares con armas como ocurre en el mundo celtibérico.

Paralelamente, el hecho de que las herramientas agropecuarias halladas sean preferentemente hoces, podaderas y tijeras de esquileo, tijeras para textiles o para uso personal, se ha considerado que podrían estar representando, por un lado, elementos simbólicos, relacionados con la economía del difunto y sus posesiones. Otra teoría derivada de que hoces y tijeras apareciesen frecuentemente en ajuares con arreos de caballo era que unas pudiesen servir para cortar forraje para alimentar a los caballos y las otras su aseo (Ortego, 1983: 575), aspecto que no consideran otros autores (Jimeno et al., 2004: 285). Por otro lado, ya se ha mencionado que se ha querido identificar como una hoz el objeto que llevan en la mano algunos jinetes de reverso de monedas datadas a finales del $s$. III y primera mitad del II a. C.; estas monedas son consideradas fruto de una tradición indígena relacionada con la divinidad local y/o el héroe fundador del grupo social que lo representa, y en particular de sus elites (Almagro-Gorbea, 1995: 259) y esos jinetes pueden ser portadores de lanzas, espadas, insignias o palmas, entre otros objetos (CNH: 211 n. 1 Bolskan; 211; 297 n. ${ }^{\circ} 1$ Uarakos; 297; 231-232 n. ${ }^{\text {s }} 1$ y 5 Sekaisa; 234 n. ${ }^{\circ} 23$ Sekaisa). Como ya hemos indicado, en monedas como las de Oilaunikos o Turiasu, se ha pensado que el jinete de reverso lleva una hoz guerrera, también llamada falx, término que significa hoz en latín, lo que a nuestro juicio implica que podía ser un utensilio utilizado con otra finalidad en caso necesario y en cualquier caso gozaba de un simbolismo propio. Reseñamos que las tumbas con este tipo de útiles en Atienza se sitúan en la periferia, a o y E; en La Mercadera se sitúan las que tienen hoz hacia el centro de la necrópolis, destacando la n. ${ }^{\circ} 3$ que carece de espada, mientras que las sepulturas con tijeras se sitúan preferentemente hacia la periferia de un eje O-E. En Numancia la tumba n. ${ }^{\circ} 144$ con podadera, $y$ sin puñal ni espada, se sitúa en la periferia $\mathrm{NE}$, al igual que las $n{ }^{\text {os }} 103$ y 132 con hoces, mientras que la $n .^{\circ}$ 139 se halla más cercana al centro. En cambio las sepulturas con tijeras se reparten por la zona nuclear y las periféricas.

Se da la circunstancia de que en ninguna de las necrópolis de esta muestra de estudio se han documentado hachas, azuelas o azadas, lo que sí ocurre en otras que como Uxama o Turmiel, que ya hemos explicado que no incluíamos por carecer sus publicaciones de planimetría clara, y también en El Castillo de Castejón, especialmente en su fase III datada entre la segunda mitad del s. IV y el III a. C. y donde se considera que también serían usadas en el ritual del sacrificio para el banquete previo a la incineración del difunto (Faro, 2015: 51-52, 110). Una interpretación similar podría darse a las azuelas documentadas en una tumba de Serra d'Almós (Tarragona) y en el túmulo z-II de la Osera 
(Ávila), ambas con sistema de sujeción mediante abrazaderas y acompañadas de ajuares con piezas excepcionales (Barril, 2002: 44). Pero la presencia de herramientas a tamaño natural o miniaturizado también podría tener una explicación más compleja, como la que propone Sanz al referirse a las herramientas miniaturizadas de las tumbas 148 y 151 de Pintia, en territorio vacceo, que le permiten hablar de "campesinos, artesanos y también guerreros" e indicar que podrían estar sintetizando la condición esencial del individuo desde una perspectiva ética o moral de una sociedad campesina que a la hora de establecer simbólicamente su personalidad para la vida ultraterrena prioriza el componente guerrero, pese que, a excepción de la aristocracia, nadie se dedicara más que ocasionalmente al manejo de las armas (Sanz, 2010: 35-357).

La presencia de elementos relacionados con el fuego en las necrópolis estudiadas es escasa y, lamentablemente, la única trébede identificada en Atienza carece de contexto de sepultura; no ocurre lo mismo con la de la sepultura 80 de Numancia, una de las de mayor relevancia de la necrópolis que está situada en la periferia septentrional de la necrópolis. En la misma zona geográfica se conocen otras piezas como sendas parrillas en La Revilla de Calatañazor y Monteagudo de las Vicarías (Lorrio, 1997: 89). En cualquier caso se trata de un tipo de objetos inicialmente de uso doméstico, pero que al haber sido hallados en tumba adquieren un significado de prestigio y se unen a rituales de banquete y sacrificio, habiéndose llegado a plantear que podían ser piezas heredadas o tesaurizadas, por lo que su pervivencia sería larga (Faro, 2015: 42). Presentan una morfología muy similar en todos los ámbitos prerromanos, tanto en el mundo ibérico (Pérez et al., 2011), como en territorio vetón o vacceo, donde se ha demostrado que este tipo de ajuares suntuarios correspondían a personajes en situación de privilegio (Górriz, 2010: 243), llegando a relacionarse con la actuación de patriarcas o jefes militares, con funciones de sacerdocio (Kurtz, 1982; Barril, 2007: 74; Baquedano, 2016: 416). Estas características son equiparables en ámbitos célticos donde pueden apreciarse por ejemplo en tumbas vetonas, como la

(c) Universidad de Salamanca tumba II del túmulo c de la zona I o la 514 de la zona vi (Kurtz, 1982: 53; Baquedano, 2016), vacceas (Górriz, 2010; Sanz, 2010) o beronas (Burillo, 2010: 580; Faro, 2015: 42).

\section{Conclusiones}

En resumen, la presencia de objetos originariamente considerados de uso en el ambiente doméstico en relación con el fuego y la preparación de alimentos o en las tareas agropecuarias y artesanales es escasa en la muestra de necrópolis seleccionadas, por ello, se presupone que su utilización estaría restringida a individuos con determinadas características. Se aprecia, sin embargo, en la muestra realizada una diferenciación entre las situadas al $\mathrm{N}$ y al $\mathrm{s}$ del eje del Jalón-Tajo, diferencia que tal vez proviene de la desigual composición y riqueza de los ajuares exhumados en una y otra área geográfica, sin que puedan valorarse las diferencias cronológicas, ya que el componente de sepulturas con apenas ajuar o carente de ajuar es muy significativo en las situadas al $s$ de hipotético citado eje. Por otro lado, la presencia de los objetos estudiados coincide en su mayoría con ajuares con armas en las situadas al $\mathrm{N}$ y además con las de mayor número de elementos de prestigio, por lo que se ha planteado que pueda tratarse de tumbas de personajes que tuviesen dentro de su comunidad unas especiales funciones, en las ceremonias comunitarias o familiares. No obstante, la situación de las tumbas que los contienen no parece tener una especial localización centro-periferia común, pero sí parece que dentro de una misma necrópolis se hallan cercanas a sepulturas con ajuares de composición similar, por lo que ese agrupamiento puede hacer suponer una relación entre los personajes enterrados, bien por razones familiares, bien sociales, lo que requeriría complementar el estudio mediante análisis interdisciplinares como los realizados sobre restos óseos en busca de ADN u otros, lo que no siempre es posible.

Este trabajo espera haber cumplido su objetivo de plantear una línea de estudio para analizar la distribución de las tumbas en el conjunto de las necrópolis, a partir de objetos relacionados con actividades 
productivas de índole doméstica, artesanal y/o utilizados en rituales, y consideramos que aunque en el ámbito que se ha planteado su presencia es mucho más reducida que en zonas como la vaccea o la vetona, su estudio puede ser relevante para conocer más sobre los pueblos prerromanos.

\section{Bibliografía}

Aguilera y Gamboa, E. de (1916): Necrópolis Ibéricas. Valladolid: Asociación para el Progreso de la Ciencia.

Almagro Gorbea, M. (1965): La necrópolis celtibérica de "Las Madrigueras», Carrascosa del Campo (Cuenca). Excavaciones Arqueológicas en España, 41. Madrid.

Almagro Gorbea, M. (1969): La necrópolis de Las Madrigueras, Carrascosa del Campo (Cuenca). Biblioteca Praeshistorica Hispana, x. Madrid: csic.

Almagro Gorbea, M. (1995): "La moneda hispánica con jinete y cabeza varonil. ¿Tradición indígena o creación romana?", Zephyrus, xLviII, pp. 235-266.

Argente, J. L. (1977): "La necrópolis celtibérica de 'El Altillo', en Aguilar de Anguita (Guadalajara) (Resultados de la campaña de excavación de 1973)", Wad-al-Hayara, 4, pp. 99-141.

Baquedano, I. (2016): La necrópolis vettona de La Osera (Ávila, España): sistematización del conjunto. Alcalá de Henares: MAR, 2 vols.

BARril, M. (1993): “¿Tumba de labrador? Celtibérico procedente de Turmiel (Guadalajara) en el MAN", Boletín del Museo Arqueológico Nacional, xI, pp. 5-16.

BARriL, M. (2002): "Los útiles agrícolas prerromanos: ideas básicas para su identificación, clasificación y adquisición de información", Sautuola, viII, pp. 33-55.

BARril, M. (2007): "En los orígenes: La metalistería prerromana”. En Fernández Ibáñez, C. (ed.): Metalistería de la Hispania romana. Sautuola, XIII, pp. 59-78.

BARRIL, M. (2012): “Tecnología punta en las culturas prerromanas peninsulares". En CASTELo, R. (ed.): $L a$ forja del hierro: una visión etnoarqueológica. Madrid: UAM, pp. 13-22.

Barril, M. y Salve, V. (2002): "Los grandes desconocidos de los ajuares de las necrópolis celtibéricas de Aguilar de Anguita (Guadalajara): bolas, fusayolas y otros posibles elementos simbólicos". En García Soto, E. y García Valero, M. Á. (eds.): Actas i Simposio de Arqueología de Guadalajara (Sigüenza, 2000). Sigüenza, vol. II, pp. 383-400.
Berzosa del Campo, R. (2005): "Utillaje y herramientas de trabajo de los celtíberos". En Jimeno, A. (ed.): Celtíberos. Tras la huella de Numancia. Soria: Diput. de Soria, pp. 319-328.

Burillo, F. (2005): "Celtiberia y celtíberos". En JimeNo, A. (ed.): Celtíberos. Tras la huella de Numancia. Soria: Diput. de Soria, pp. 61-72.

Burillo, F. (2010): "Vino y ritual en la Celtiberia". En Burillo, F. (ed.): IV Simposio sobre celtíberos. Ritos y mitos. Zaragoza, pp. 573-593.

CABré, J. (1917): Catálogo arqueológico, histórico, artístico y monumental de la provincia de Soria. Vol. III. Necrópolis celtibéricas. Madrid.

CABRÉ, J. (1930): Excavaciones en la necrópolis celtibérica del Altillo de Cerropozo, Atienza (Guadalajara). Memorias de la Junta Superior de Excavaciones y Antigüedades, 105. Madrid.

Casas, M.; Morín de Pablos, J. y Urbina, D. (2012): "Análisis palinológico del yacimiento arqueológico de Las Madrigueras II (Carrascosa del Campo, Cuenca)", Polen, 22, pp. 15-24.

Cerdeño, M. L. y García Huerta, R. (2001): "Las necrópolis celtibéricas: nuevas perspectivas de estudio". En García Huerta, R. y Morales, F. J. (coords.): Arqueología funeraria: las necrópolis de incineración. Ciudad Real: UCLM, pp. 141-190.

Cerdeño, M. L. y Sargadoy, T. (2007): La necrópolis celtibérica de Herrería III y IV (Guadalajara). Zaragoza: Centro de Estudios Celtibéricos de Segeda.

Chapa, T. y Mayoral, V. (2007): Arqueología del trabajo. El ciclo de la vida en un poblado ibérico. Madrid: Akal Arqueología.

$\mathrm{CNH}=$ VilLARONGA, L. (1994).

Cuadrado, E. (1968): Excavaciones en la necrópolis celtibérica de Riba de Saelices (Guadalajara). Excavaciones Arqueológicas en España, 60. Madrid.

Faro, J. A. (2015): "La necrópolis de El Castillo (Castejón, Navarra). Vajilla e instrumental metálico de sacrificio y banquete en el valle medio del Ebro (ss. VI-III a. C.)", Lucentum, 34, pp. 31-118.

Fuentes, C. (2011): La necrópolis celtibérica de Viñas de Portugui (Osma, Soria). Noia: Edit. Toxosoutos.

García Huerta, R. y Antona del Val, V. (1992): Excavaciones arqueológicas: La Yunta (Guadalajara). Campañas 1984-1987. Patrimonio Histórico-Arqueología, 4. Valladolid.

Górriz, C. (2010): "Rituales de vino y banquete en la necrópolis de Las Ruedas de Pintia". En Romero, F. y SANZ, C. (eds.): De la región vaccea a la arqueología vaccea. Valladolid: Centros de Estudios Vacceos F. Wattenberg de la Univ. de Valladolid, pp. 231-256. 
GuAdán, A. M. (1979): Las armas en la moneda ibérica. Cuadernos de Numismática. Madrid.

Jimeno, A.; De la Torre, I.; Berzosa, R. y Martínez, J. P. (2004): La necrópolis celtibérica de Numancia. Arqueología en Castilla y León, 12. Valladolid: JCyL

KurTz, W. S. (1982): "Material relacionado con el fuego aparecido en la necrópolis de Las Cogotas y de La Osera", Boletín de la Asociación Española de Amigos de la Arqueología, 16, pp. 52-54.

Lorrio, A. (1990): “La Mercadera (Soria): Organización social y distribución de la riqueza en una necrópolis celtibérica". En Necrópolis celtibéricas. II Simposio sobre celtiberos. Zaragoza: Instit. Fernando el Católico, pp. 39-50.

Lorrio, A. (1997): Los celtiberos. Complutum Extra, 7. Madrid.

LoRRIO, A. (2007): "Historiografía y nuevas interpretaciones: la necrópolis de la Edad del Hierro de Haza del Arca (Uclés, Cuenca)”, Caesaraugusta, 78, pp. 251-278.

Mateos, C. M. y SÁnchez Nicolás, D. (2014): "El cuchillo afalcatado. Análisis tipológico y funcional de los cuchillos de los yacimientos abulenses durante la in Edad del Hierro". En González, E.; Paniagua, E. e INÉs, P. DE (coords.): Investigaciones Arqueológicas en el valle del Duero, del Paleolitico a la Antigüedad Tardía. Actas III Jornadas de Jóvenes Investigadores del Valle del Duero (Salamanca, 2013), vol. 3, pp. 135150 (http://dialnet.unirioja.es/servlet/articulo?codigo=5048536) [consulta 9-11-15]).

Ortego, T. (1983): "La Necrópolis Arévaca de la Revilla (Soria)". En Actas XVI CAN (1982, Murcia). Zaragoza, pp. 573-584.
Pérez Jordá, G.; Ferrer, C.; Iborra, P.; Ferrer, M. A.; Carrión, Y.; Tortajada, G. y Soria, L. (2011): "El trabajo cotidiano. Los recursos agropecuarios, la metalurgia, el uso de la madera y las fibras vegetales". En Bonet, H. y Vives-Ferrándiz, J. (eds.): La Bastida de les Alcusses. Valencia: MPV, pp. 94-137.

Quesada, F. (1997): El armamento ibérico. Estudio tipológico, geográfico, funcional, social, y simbólico de las armas en la Cultura Ibérica (siglos VI-I a. C.). Montagnac: Édit. Monique Mergoil, 2 vols.

Ruiz Zapatero, G. (2005): "Los Celtas en Europa". En Jimeno, A. (ed.): Celtíberos. Tras la estela de Numancia. Soria: Diput. de Soria, pp. 21-28.

SAnZ, C. (2010): "El armamento vacceo". En RomeRO, F. y SANZ, C. (eds.): De la región vaccea a la arqueología vaccea. Valladolid: Centros de Estudios Vacceos F. Wattenberg de la Univ. de Valladolid, pp. 319-358.

TARACENA, B. (1932): Excavaciones en la provincia de Soria. La Mercadera. Memorias de la Junta Superior de Excavaciones y Antigüedades, 119. Madrid.

Urbina, D. y Urquijo, C. (2007): "Cerro Colorado, Villatobas, Toledo. Una necrópolis de incineración en el Centro de la Península". En Estudios sobre la Edad del Hierro en la Carpetania. Zona Arqueológica, 10, pp. 239-254.

Urbina, D. y Urquijo, C. (2015): Objetos y personas. La necrópolis de Cerro Colorado y la Arqueología de la Edad del Hierro en la Meseta Sur. Bibliotheca Praehistorica Hispana, Xxx. Madrid: Csic.

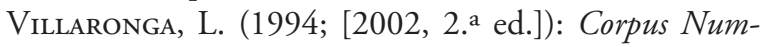
mum Hispaniae ante Augusti aetatem. Barcelona. 
